The Free Internet Journal

for Organic Chemistry
Paper

Arkivoc 2019, part iv, 0-0

to be inserted by editorial office

\title{
Comparison of affinity ranking by target-directed dynamic combinatorial chemistry and surface plasmon resonance
}

\author{
Priska Frei, Marleen Silbermann, Tobias Mühlethaler, Xiaohua Jiang, \\ Oliver Schwardt, Rachel Hevey, and Beat Ernst*
}

Department of Pharmaceutical Sciences, University of Basel, Klingelbergstr. 50, CH-4056 Basel, Switzerland E-mail: Beat.Ernst@unibas.ch

Dedicated to Steven Hanessian, for his friendship and support over many years

Received 02-20-2019

Accepted 04-21-2019

Published on line 05-02-2019

\section{Abstract}

Target-directed dynamic combinatorial chemistry (tdDCC) is a powerful method to screen ligands for pharmacologically relevant targets. Generating a dynamic library from reversibly reacting building blocks in the presence of a target protein leads to the amplification of the most potent library constituents. In previous studies on tdDCC, these compounds were identified in a qualitative "hit/no-hit"-manner. However, the precise relationship between the degree of amplification and the affinity of the library constituent has not yet been evaluated. To study the amplification-affinity relationship, we compared tdDCC experiments, employing reversible acylhydrazone formation and the bacterial adhesin FimH as a target, with affinities of the library constituents as determined by surface plasmon resonance.

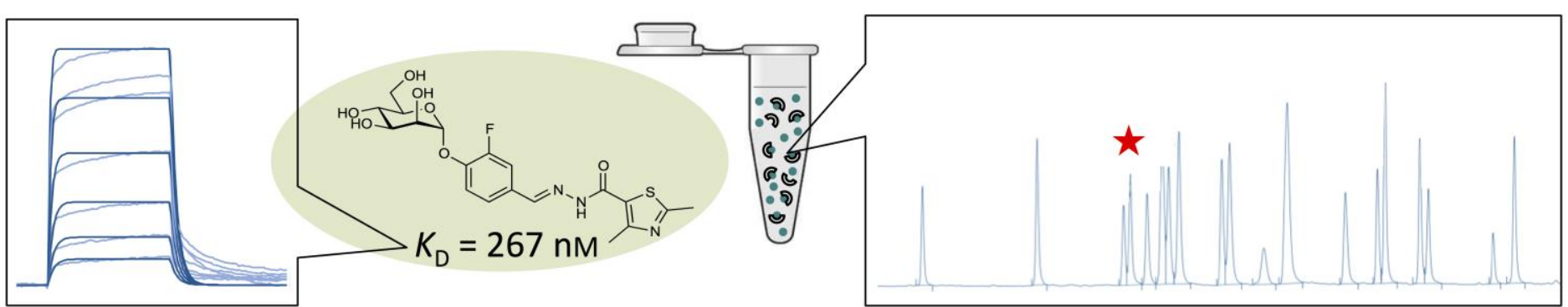

Keywords: Acylhydrazone, FimH antagonists, dynamic combinatorial chemistry, supramolecular chemistry, drug discovery 


\section{Introduction}

Dynamic combinatorial chemistry (DCC) describes the generation of dynamic compound libraries from reversibly reacting building blocks. These libraries, which are under thermodynamic control, remain adaptive by continuous interconversion of building blocks and products. Therefore, addition of a protein target alters their equilibrium composition by binding, thereby stabilizing, and ultimately amplifying specific library constituents. Target-directed DCC (tdDCC) exhibits a self-screening ability, leading to the amplification of those members of the library with the highest affinity for the protein target, as depicted for an acylhydrazone library in Figure 1. This makes tdDCC a valuable tool for drug discovery. ${ }^{1-6}$

Hydrazide and aldehyde building blocks
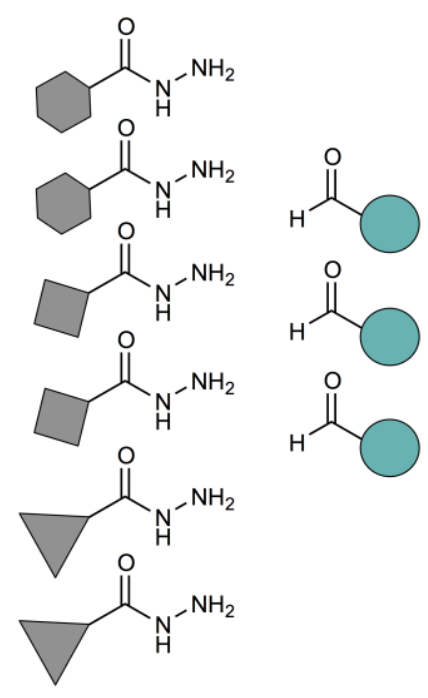

Dynamic acylhydrazone library

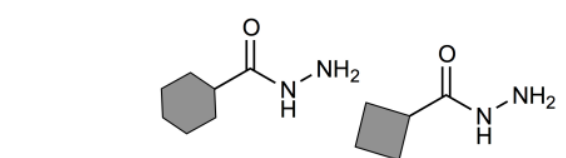

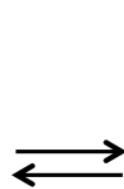
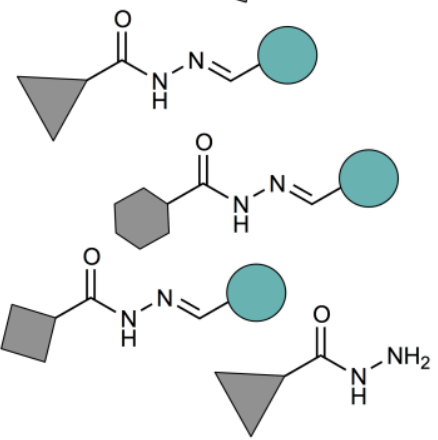

Selection by the bacterial adhesin FimH and amplification of selected compound

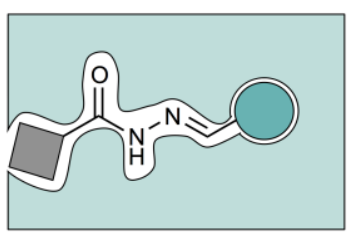

Figure 1. Schematic illustration of tdDCC. Reversibly reacting hydrazide and aldehyde building blocks generate a dynamic acylhydrazone library, which, when challenged with the target FimH, responds with a shift in its equilibrium composition including amplification of selected high-affinity ligands.

Whereas earlier reports focused on small libraries in a qualitative "hit/no-hit"-manner, ${ }^{3-6}$ a more precise affinity ranking is required to increase the value of tdDCC. So far, the relationship between the extent of amplification and affinity was addressed in detail only by Nasr et al. ${ }^{7}$ Furthermore, it has been noted that if several library constituents exhibit high affinity, the identification of the best binders might be difficult. ${ }^{8}$ Finally, theoretical considerations regarding the relationship between host-ligand interactions and extent of amplification have been reported. ${ }^{9}$

In this communication, we have examined in greater detail the relationship between the amplification of library members in $\operatorname{tdDCC}$ experiments and their dissociation constants $\left(K_{\mathrm{D}}\right)$. As target protein we selected the bacterial adhesin FimH, located at the distal tip of type 1 pili of uropathogenic $E$. coli (UPEC) strains, which are the cause of the majority of urinary tract infections (UTI). ${ }^{10-12}$ In the initial step of infection, FimH binds to the highly mannosylated surface protein uroplakin $1 \mathrm{a}$ on urothelial host cells, ${ }^{13}$ a process which can be prevented with FimH antagonists such as aryl mannosides. ${ }^{14-20}$

We have reported previously that in addition to ligand affinity, also the ratio of scaffold to fragment building blocks, sample preparation, analysis, and method of data processing can be crucial factors in dictating experiment success. ${ }^{21}$ Here, we extend the reported protocol for tdDCC using the bacterial adhesin FimH as 
target protein to a larger scale. When aldehyde scaffold $\mathbf{1}^{21}$ reacts reversibly with hydrazide fragments $\mathbf{2 a - u}$ ( $\rightarrow$ 3a-u; Scheme 1), the acylhydrazone library $\mathbf{3 a - u}$ is obtained. At neutral pH in aqueous media, equilibrium formation is facilitated by aniline as a nucleophilic catalyst. ${ }^{22}$
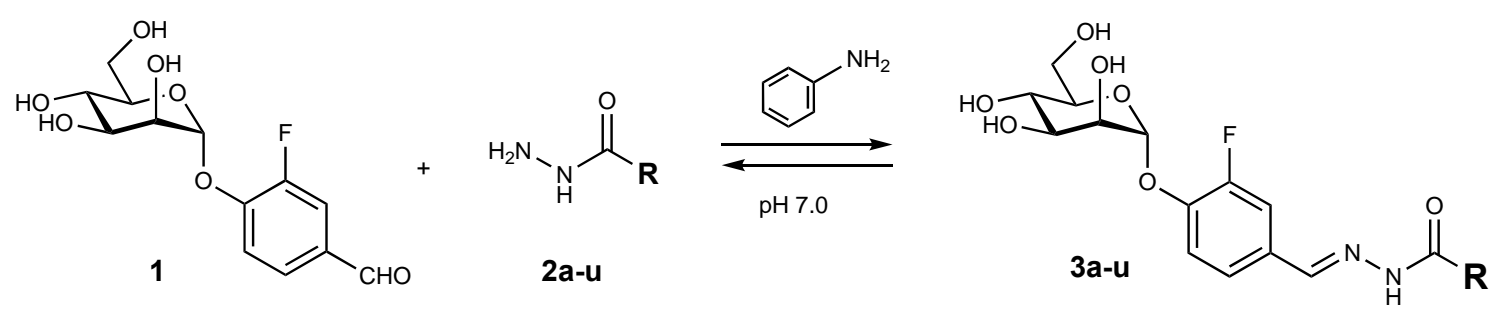

R:<smiles>CC(C)(N)c1cccnc1</smiles><smiles>Cc1ccco1</smiles>

b<smiles>Cc1occc1C(C)(C)C</smiles><smiles>Cc1cccs1</smiles>

h<smiles>CC(C)(C)c1ccc(Cl)cc1</smiles>

o<smiles>Cc1csc(C(C)(C)C)c1Cl</smiles>

p<smiles>Cc1ncc(C(C)(C)C)s1</smiles><smiles>Cc1nc(C)c([Y](C)(C)C)s1</smiles>

d<smiles>COc1ccc(C(C)(C)C)cc1</smiles><smiles>CC(C)(C)c1cc2ccccc2[nH]1</smiles>

k<smiles>CC(C)(C)c1ccc(Cl)s1</smiles>

q<smiles>Cc1ccc2ccccc2c1</smiles>

r<smiles>CC(C)(C)c1ccc(Cl)nc1</smiles>

e<smiles>CC(C)(C)Cc1c[nH]c2ccccc12</smiles>

I<smiles>CC(C)(C)c1ccc(C(F)(F)F)cc1</smiles>

s<smiles>CC(C)(C)c1ccccc1</smiles>

f<smiles>Cc1ccc(C(C)(C)C)cc1</smiles><smiles>Cc1sc2ccccc2c1Cl</smiles>

t<smiles>Cc1ccc(C(C)(C)C)s1</smiles>

n<smiles>Cn1cccc1C(C)(C)C</smiles>

g

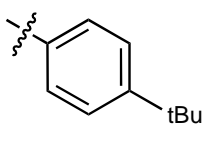

$\mathbf{u}$

Scheme 1. Aldehyde scaffold $\mathbf{1}$ and hydrazide fragments $\mathbf{2 a - u}$ used for the reversible generation of acylhydrazones $\mathbf{3 a}-\mathbf{u}$ at neutral $\mathrm{pH}$ with aniline promotion.

Equilibration was carried out in the absence (blank library) or presence (template library) of biotinylated full-length FimH (FimH $\left.\mathrm{FL}_{\mathrm{B}}\right)^{23}$ for three days. ${ }^{21}$ The reversibility of the acylhydrazone exchange reaction was then blocked by an adjustment in $\mathrm{pH}$, which effectively locks in the library composition and renders the library suitable for analysis. ${ }^{24}$ Prior to UV-HPLC analysis, the protein-ligand complex was captured using commercially available streptavidin agarose, and any unbound ligand removed from the sample (Figure $2 \mathrm{~A}$ and $2 \mathrm{~B}$ ). The protein-bound ligand was then released by a further increase in $\mathrm{pH}$ together with addition of the Fim $\mathrm{H}$ antagonist $n$-heptyl $\alpha$-D-mannopyranoside ${ }^{25}$ (4, Figure $2 \mathrm{C}$ ). The supernatant was then analyzed with HPLC and the chromatograms of template libraries compared to those of equally treated blank samples.

On account of toxicological and stability concerns over the acylhydrazone moiety, we subsequently explored its potential for bioisosteric replacement. 


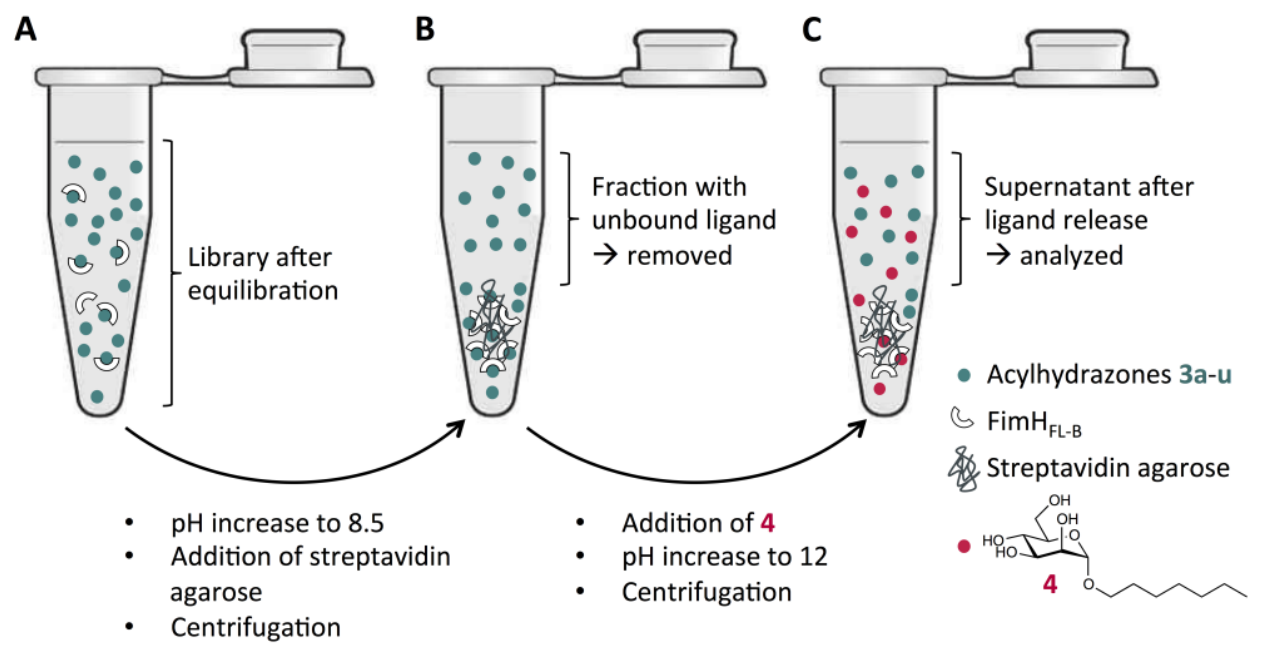

Figure 2. Schematic representation of the experimental tdDCC set-up. ${ }^{21}$
A. After sufficient equilibration, the library composition is made static through a $\mathrm{pH}$ increase $(\mathrm{pH} 8.5)$, and then the biotinylated target protein - including bound ligands - is captured with commercially available streptavidin agarose.
B. After centrifugation, the supernatant (containing unbound ligands) is discarded and the agarose- protein-ligand complex resuspended.
C. Bound ligands are released from the captured FimH into bulk solvent by the addition of excess of $n$-heptyl $\alpha$-D-mannopyranoside (4) ${ }^{25}$ and a further $\mathrm{pH}$ increase $(\mathrm{pH} 12)$. After a final centrifugation step, the supernatant is removed and analyzed by HPLC.

\section{Results and Discussion}

\section{Target-directed dynamic combinatorial chemistry (tdDCC)}

Because the outcomes of tdDCC experiments are influenced not only by the ratio of scaffolds to fragments, ${ }^{21}$ but also by the ratio of library constituents to target protein, ${ }^{26}$ we studied this issue in more detail by employing different amounts of building blocks, while keeping the protein concentration constant. Dynamic libraries were generated with varying concentrations of aldehyde scaffold 1 (600 $\mu \mathrm{M}, 400 \mu \mathrm{M}$, and $200 \mu \mathrm{M})$ together with hydrazide fragments $2 \mathrm{a}-\mathbf{u}$ each at $100 \mu \mathrm{M}$. All libraries were equilibrated in the presence and absence of $100 \mu \mathrm{M}$ FimH $_{\mathrm{FL}-\mathrm{B}}$ (measured in triplicates). In this experimental design, the amount of scaffold 1 is determining the maximum attainable acylhydrazone concentration. Assuming full conversion of the aldehyde, facilitated by the addition of excess hydrazides, concentration ratios of $6: 1,4: 1$, and 2:1 between acylhydrazones and target protein should be reached. With a 1:1 ratio, accurate detection was not possible due to an insufficient amount of acylhydrazones, while unsatisfactory solubility became an issue at higher protein concentrations. The libraries were analyzed by UV-HPLC, detecting optical density at $310 \mathrm{~nm}$. Conveniently, only acylhydrazones absorb UV light at this particular wavelength, but not other library constituents such as aniline, unreacted hydrazides, or $n$-heptyl $\alpha$-D-mannopyranoside (4). Peaks in the resulting chromatograms were assigned using reference samples. Because both $\mathbf{3} \mathbf{f}$ and $\mathbf{3 g}$, as well as $\mathbf{3 m}$ and 3n, gave overlapping signals which could not be resolved, we treated these signals as containing equal amounts of both constituents. 
Composition of each library was determined based on the relative peak area (RPA), where the summated peak areas in each chromatogram were set to $100 \%$ and each peak assigned its fraction. Based on this information, the normalized change of $R P A^{21}$ between template and blank samples could be calculated and the influence of $\mathrm{FimH}_{\mathrm{FL}-\mathrm{B}}$ on the library composition assessed (Figure 3). A positive value indicates amplification of a compound in the presence of $\mathrm{FimH}_{\mathrm{FL}-\mathrm{B}}$, whereas a negative value indicates depletion.

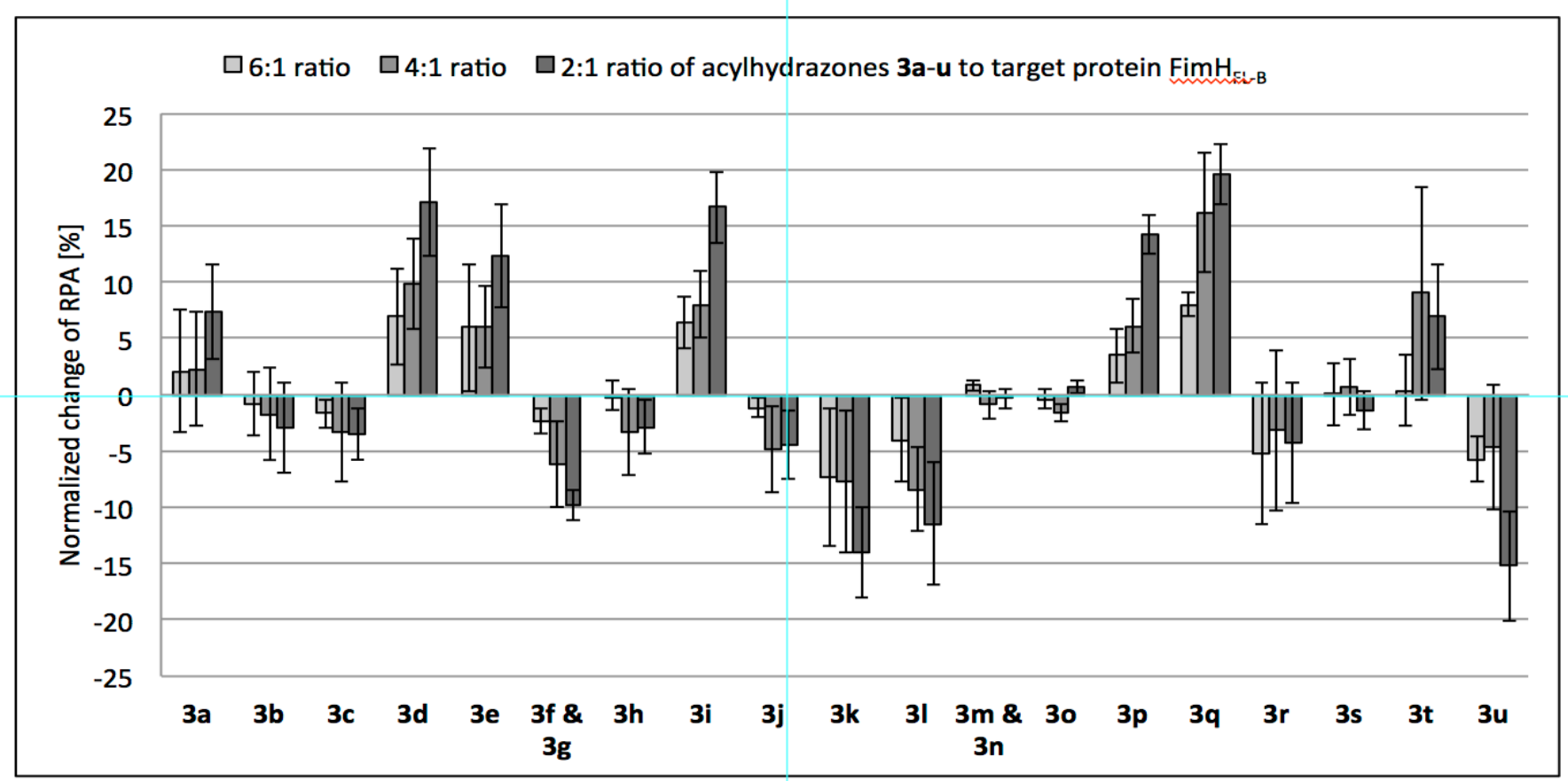

Figure 3. Normalized change of $R P A^{21}$ between template and blank libraries. Bars from light to dark grey indicate $6: 1,4: 1$, and 2:1 concentration ratios of total acylhydrazones to FimH $_{\mathrm{FL}-\mathrm{B} \text {. Triplicates of all }}$ libraries were generated in the presence and absence of $100 \mu \mathrm{M}$ FimH $\mathrm{FL}_{\mathrm{BL}}$. Error bars indicate error propagation of standard deviations of RPAs over three measurements. ${ }^{21}$

The most pronounced influence of $\mathrm{FimH}_{\mathrm{FL}-\mathrm{B}}$ on the library composition was observed when core aldehyde 1 was present at $200 \mu \mathrm{M}$, resulting in a 2:1 ratio of acylhydrazones to target protein. When the scaffold was employed at higher concentrations ( $400 \mu \mathrm{M}$ and $600 \mu \mathrm{M})$, changes in composition of the libraries were less pronounced. To evaluate if the normalized changes of RPA correlated with the affinities of the corresponding acylhydrazones, $K_{\mathrm{D}}$ values for $\mathbf{3 a}$-u were determined by surface plasmon resonance (SPR) using a previously established procedure. ${ }^{21}$ Owing to the structural similarity of the compounds, differences in observed $K_{D}$ values were not drastic (267 nM to $760 \mathrm{~nm}$; Table 1). Obviously, this narrow distribution of affinities places highest demands on the applied analytical tools. 
Table 1. Affinities measured by surface plasmon resonance.

\begin{tabular}{cccc}
\hline Compound & $\boldsymbol{K}_{\mathrm{D}}[\mathrm{nM}]$ & $\begin{array}{c}\text { Compoun } \\
\mathbf{d}\end{array}$ & $\boldsymbol{K}_{\mathrm{D}}[\mathrm{nM}]$ \\
\hline $\mathbf{1}$ & $3160^{21}$ & $\mathbf{3 k}$ & 427 \\
$\mathbf{3 a}$ & 359 & $\mathbf{3 l}$ & 508 \\
$\mathbf{3 b}$ & $520^{21}$ & $\mathbf{3 m}$ & 484 \\
$\mathbf{3 c}$ & 358 & $\mathbf{3 n}$ & 390 \\
$\mathbf{3 d}$ & 267 & $\mathbf{3 0}$ & 440 \\
$\mathbf{3 e}$ & 492 & $\mathbf{3 p}$ & 377 \\
$\mathbf{3 f}$ & $550^{21}$ & $\mathbf{3 q}$ & 286 \\
$\mathbf{3 g}$ & 461 & $\mathbf{3 r}$ & 337 \\
$\mathbf{3 h}$ & 642 & $\mathbf{3 s}$ & 536 \\
$\mathbf{3 i}$ & $330^{21}$ & $\mathbf{3 t}$ & 376 \\
$\mathbf{3 j}$ & 462 & $\mathbf{3 u}$ & $760^{21}$ \\
\hline
\end{tabular}

Results of tdDCC experiments are commonly reported in a "hit/no-hit"-manner. Amplification ("hit") and depletion ("no-hit") were only considered significant when the propagated error did not cross the baseline (Figure 3). Otherwise, compound concentrations were regarded as unchanged. Ligands $\mathbf{3 d} \mathbf{d} \mathbf{3 i}, \mathbf{3 p}$ and $\mathbf{3 q}$ were amplified by the target in each of the three described experimental designs, whereas $\mathbf{3 a}$ and $\mathbf{3 t}$ were only amplified in the replicates with a 2:1 acylhydrazones to $\mathrm{FimH}_{\mathrm{FL}-\mathrm{B}}$ ratio. The investigation of compounds with a negative normalized change of RPA revealed that signals $\mathbf{3 l}$, $\mathbf{3} \mathbf{u}$, and overlapping $\mathbf{3} \mathbf{f}$ and $\mathbf{3 g}$ were decreased, in accordance with lower affinities. For acylhydrazones with intermediate affinities, the combined signal of $\mathbf{3 m}$ and $3 \mathrm{n}$ stayed unchanged with $200 \mu \mathrm{M}$ and $400 \mu \mathrm{M}$, but was slightly increased with $600 \mu \mathrm{M}$ of core aldehyde 1. Finally, 3j ( $K_{\mathrm{D}}$ of $462 \mathrm{nM}$ ) and 30 ( $K_{\mathrm{D}}$ of $440 \mathrm{nM}$ ) remained unchanged in all libraries. 


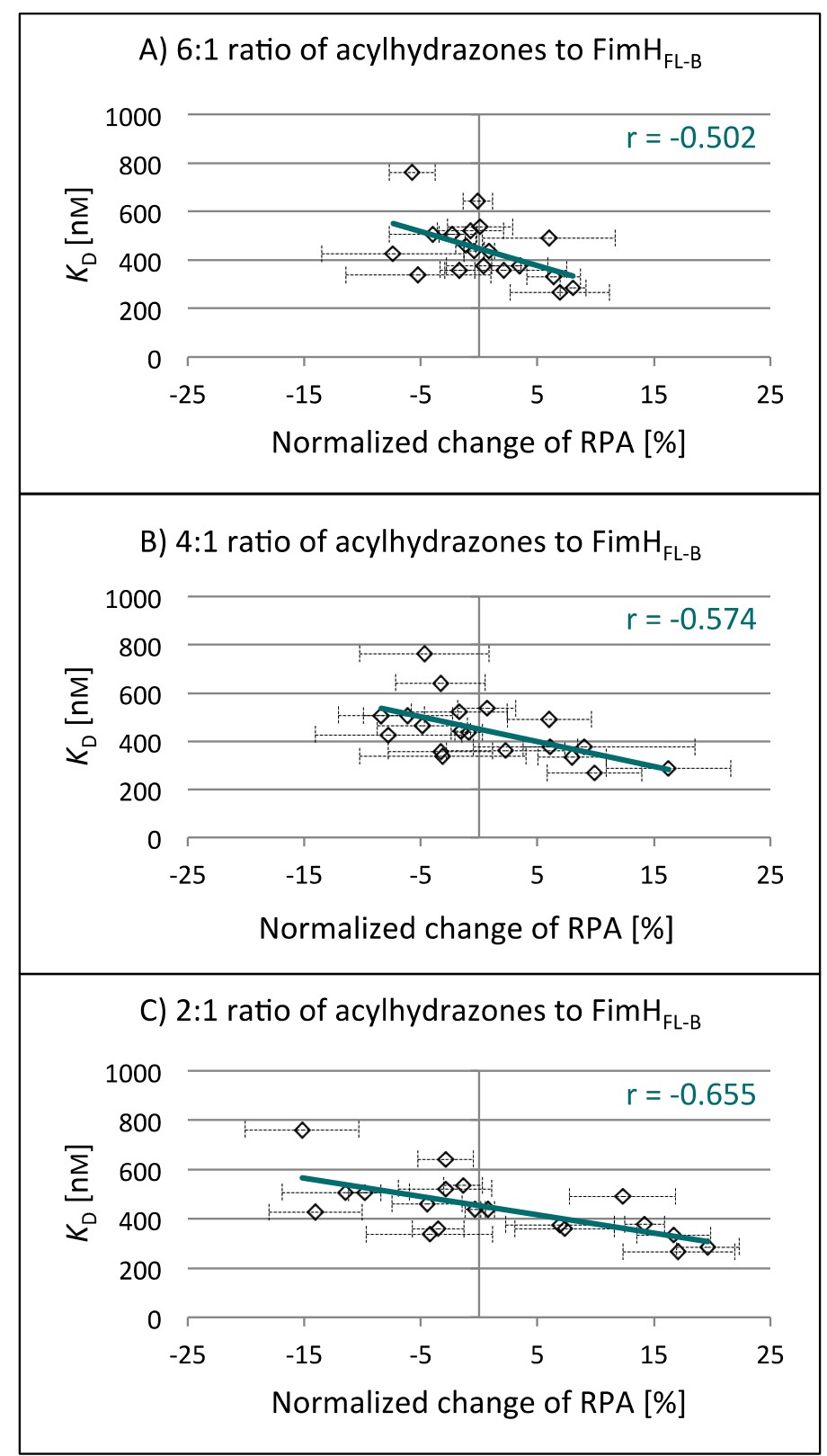

Figure 4. Quantitative relationship between the normalized change of relative peak area (RPA) and the dissociation constant $\left(K_{\mathrm{D}}\right)$ for different acylhydrazones. Pearson's correlation coefficient $r$ is given as a measure of alignment.

Even though the majority of normalized changes of RPA correlated with the affinity data obtained by SPR, deviations were found for some acylhydrazones: albeit exhibiting rather high affinities of $358 \mathrm{nM}$ and $337 \mathrm{nM}$, the normalized changes of RPA for $3 \mathrm{c}$ and $3 \mathrm{r}$ remained unchanged, while $3 \mathrm{e}$ with a $K_{\mathrm{D}}$ of only $492 \mathrm{nM}$ was amplified. Furthermore, 3b, 3h, and 3s with rather low affinities of $523 \mathrm{nM}, 642 \mathrm{nM}$, and $536 \mathrm{nM}$, respectively, remained unchanged, whereas 3k with an affinity of $427 \mathrm{nM}$ was decreased. Some of these aberrations could potentially result from the fast binding kinetics (both on- and off-rates) between acylhydrazones and FimH $\mathrm{FL}_{\mathrm{F}}$, as was observed in the SPR experiments (see Supporting Information). Since the kinetic constants could not be uniquely determined in all cases, some of the reported $K_{\mathrm{D}}$ values may be erroneous. Apart from the fast binding kinetics ${ }^{21}$ which may have impeded the SPR measurements, we currently have no explanation for these outliers. However, it is important to keep in mind that when different techniques for affinity 
measurements are utilized, deviations resulting from some inherent errors of measurements are often unavoidable.

To assess the quantitative relationship between $\operatorname{tdDCC}$ and SPR results, the normalized change of RPA for each acylhydrazone was plotted against its $K_{D}$ value. In the case of overlapping signals in the tdDCC experiment, the $K_{\mathrm{D}}$ value used was the average of the two acylhydrazones. Linear regression of the experimental data obtained using a 6:1 substrate ratio showed a moderate Pearson's correlation coefficient ( $r$ ) of -0.502 (Figure $4 A$ ). For the $4: 1$ substrate ratio, the correlation coefficient slightly increased to -0.574 (Figure $4 \mathrm{~B})$, and for the 2:1 ratio, the highest correlation with an $r$-value of -0.655 was obtained (Figure $4 \mathrm{C}$ ).

Overall, the tdDCC experiments delivered results comparable to SPR. Given the narrow range of $K_{\mathrm{D}}$-values in the compound series, this clearly highlights the sensitivity of tdDCC. Furthermore, the tdDCC approach offers great economy of time: while SPR often requires independent synthesis and purification prior to affinity measurement, tdDCC combines the two steps into a single assay, thus clearly accelerating the process of hit identification. An additional benefit is that the described tdDCC protocol requires only standard laboratory equipment, while SPR requires an elaborate and costly instrument.

\section{Bioisosteric replacement}

Besides their use in $\operatorname{tdDCC},{ }^{21,24,27-31}$ several acylhydrazones have been reported to exhibit therapeutic properties $^{32}$ in areas such as cancer, ${ }^{33-34}$ viral $^{35-36}$ and bacterial ${ }^{37-38}$ infection, and pain and inflammation. ${ }^{39}$ Furthermore, hydrazone linkages have been exploited for $\mathrm{pH}$-responsive drug delivery. ${ }^{40}$ However, both the cytotoxic activity inherently linked to anti-cancer drugs and the instability of the hydrazone moiety which affords its $\mathrm{pH}$-responsiveness give rise to general concerns towards inclusion of the acylhydrazone group in potential FimH antagonists. Jumde et al. recently reported on bioisosteric replacement of the acylhydrazone moiety. ${ }^{41}$ Therefore, in an effort to improve on stability and reduce toxicity, we generated a small library of bioisosteric analogues.

To explore possible bioisosteres of acylhydrazone, six alternatives to $\mathbf{3 f}$ were synthesized $(\rightarrow \mathbf{5 - 1 0}$; Table 2). Conveniently, reduction of $\mathbf{3 f}$ with $\mathrm{NaBH}_{3} \mathrm{CN}$ yielded hydrazide $\mathbf{5}$. Ureas $\mathbf{6}$ and $\mathbf{7}$ were synthesized from the corresponding anilines and amines, which were coupled via intermediates formed from 4nitrophenyl chloroformate. Thioureas $\mathbf{8}$ and $\mathbf{9}$ were generated from the same aniline and amine starting materials through activation with 1,1'-thiocarbonyldiimidazole. Lastly, amide $\mathbf{1 0}$ was obtained by first assembling the aglycone from acid and amine precursors using standard peptide coupling, followed by mannosylation.

The affinities of compounds 5-10 were evaluated in a competitive fluorescence polarization assay (FPA), ${ }^{14,17}$ using a non-biotinylated version of the FimH full-length protein ( $\left.\mathrm{FimH}_{\mathrm{FL}}\right){ }^{23}$ In type 1 pili of UPECs, the FimH subunit is stabilized by the $\mathrm{N}$-terminal donor strand of the adjacent FimG subunit. Because isolated FimH turned out to be unstable, FimH $\mathrm{FL}_{\mathrm{B}}$ and $\mathrm{FimH}_{\mathrm{FL}}$ required stabilization by a peptide consisting of the 15 terminal amino acids of FimG which mimics the donor strand. In the case of FimH $\mathrm{FL}_{\mathrm{B}}$, biotin was linked to the pentadecapeptide, which does not alter $\mathrm{FimH}_{\mathrm{FL}-\mathrm{B}}$ 's binding properties as compared to FimH $\mathrm{FL}_{\mathrm{FL}}$. Hence, affinities determined with either of the constructs should be comparable. In the competitive FPA, the compounds under investigation displace a fluorescently labeled FimH antagonist (see $\mathbf{1 1}$ in the Supporting Information) ${ }^{14}$ whose fluorescence polarization depends on target binding. By running a ligand dilution series, the dissociation constants could be determined and are summarized in Table 2. For 3f, a $K_{\mathrm{D}}$ value of $515 \mathrm{nM}$ was obtained, which is in excellent agreement with the affinity measured by SPR (550 nM; Table 1). All bioisosteres except for amide 10 exhibited a diminished affinity for FimH $_{\mathrm{FL}}$. Noteworthy, only when the benzoyl moiety of the acylhydrazone was preserved as in hydrazide 5 and amide 10, a strong loss of affinity could be avoided. 
In summary, as evidenced by antagonist 10, and as described by Jumde et al. ${ }^{41}$ replacement by an amide provides a good starting point for further optimization of acylhydrazones.

Table 2. Dissociation constant $K_{\mathrm{D}}$ and relative $K_{\mathrm{D}}\left(r K_{\mathrm{D}}\right)$ as determined with the fluorescece polarization assay.

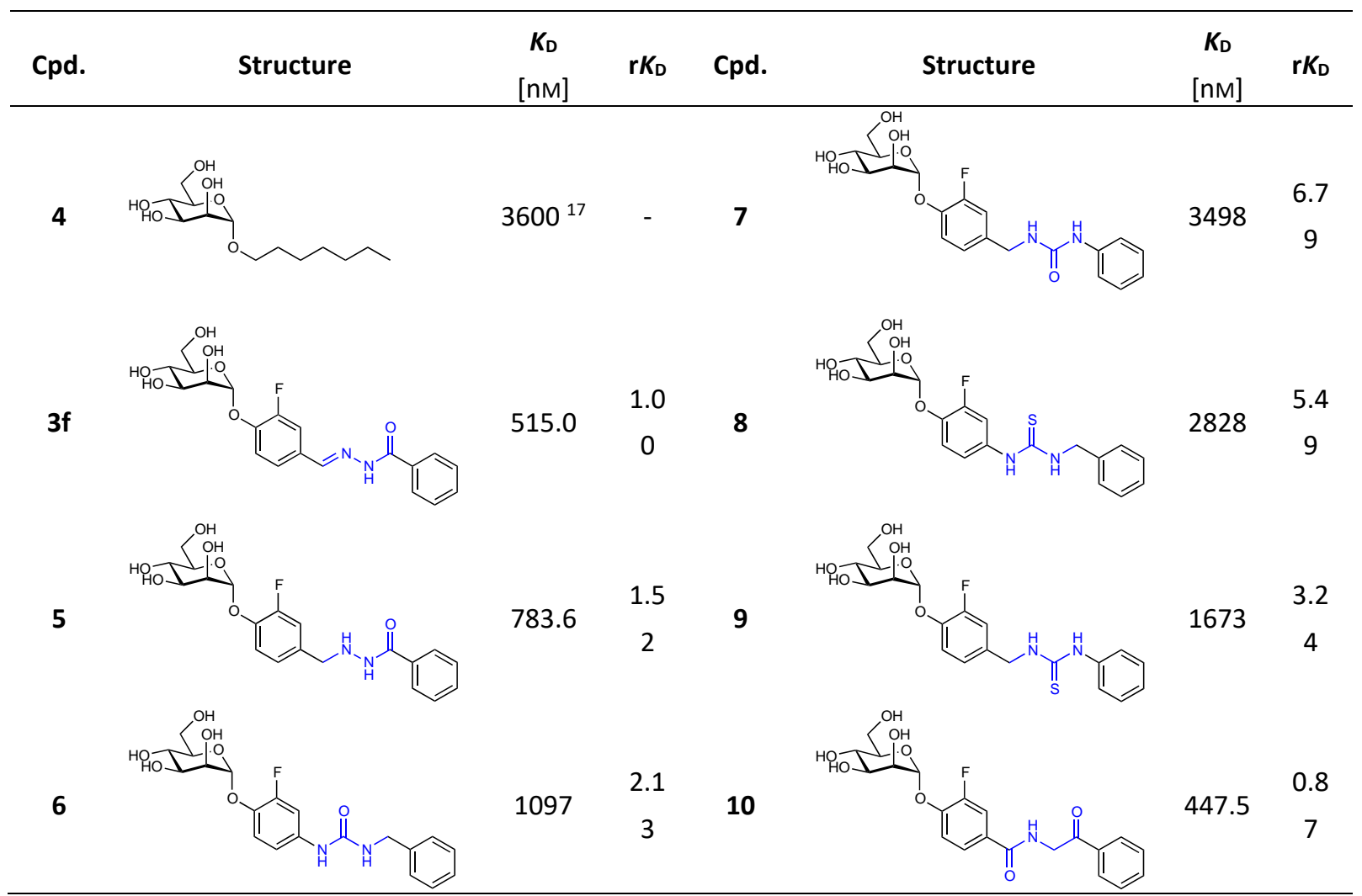

\section{Conclusions}

In tdDCC experiments, the resulting composition is generally only qualitatively ranked in a "hit/no-hit"manner. One goal of this communication was to explore whether a tdDCC ranking correlated to an affinity ranking that had been determined using surface plasmon resonance (SPR) experiments. We therefore established a 21-membered acylhydrazone library using aldehyde scaffold $\mathbf{1}$ and the commercially available hydrazide fragments $\mathbf{2 a - u}(\rightarrow \mathbf{3 a}-\mathbf{u})$. TdDCC acylhydrazone libraries were generated both in the absence and

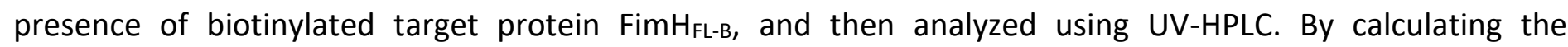
normalized changes of relative peak area (RPA) between template and blank libraries, the influence of Fim $\mathrm{H}_{\mathrm{FL}-\mathrm{B}}$ could be assessed. Surprisingly, the library composition observed post-equilibration was influenced by the acylhydrazones/FimH $\mathrm{FL}_{\mathrm{B}}$ ratio $(6: 1,4: 1$, and $2: 1)$, where differences between components became more enhanced with greater relative amounts of $\mathrm{FimH}_{\mathrm{FL}-\mathrm{B}}$ (i.e. up- or down-regulation was more pronounced). When the tdDCC results were qualitatively ranked in a "hit/no-hit"-manner, the majority of amplified acylhydrazones indeed also exhibited high affinities in SPR experiments, whereas lower $K_{\mathrm{D}}$ s correlated with down-regulated compounds. Next, when the normalized changes of RPA were plotted against $K_{\mathrm{D}}$ values, a linear correlation was observed. The best alignment was obtained from the libraries with a 2:1 ratio of acylhydrazone to protein target, but the correlation was diminished when libraries with the 4:1 and 6:1 ratios were evaluated. These results suggest that a stoichiometric ratio between library constituents and target protein would be ideal for the generation of libraries in which all members exhibit affinity. However, different ratios are conceivable for 
libraries, which cover a wider range of affinities. In a situation where only a few good binders are present, their formation would more efficiently outcompete the others.

In subsequent efforts, replacement of the potentially hazardous acylhydrazone moiety with various bioisosteres was investigated. Whereas urea $(\rightarrow 6$ and 7$)$ and thiourea $(\rightarrow 8$ and 9$)$ analogues of parent compound $\mathbf{3 f}$ exhibited decreased affinities, hydrazide derivative $\mathbf{5}$ retained affinity and amide analogue $\mathbf{1 0}$ mildly enhanced the affinity, indicating that the latter two bioisosteres could represent a good starting point for further optimization of acylhydrazone hits from tdDCC.

In summary, applying tdDCC to $\mathrm{FimH}_{\mathrm{FL}-\mathrm{B}}$ using acylhydrazone libraries of structurally related mannosides successfully confirmed the high sensitivity of this approach. Most importantly, a linear association between the normalized change of RPA and the $K_{\mathrm{D}}$ values determined by SPR could be observed.

\section{Experimental Section}

General. Affinity values were determined using a Biacore T200 system (GE Healthcare). UV-HPLC measurements were made using an Agilent 1100/1200 system (Agilent). FPA was measured on a Synergy H1 hybrid multimode microplate reader (BioTek Instruments Inc., Winooski, VT, USA).

FPA, ${ }^{14,17}$ protein production, ${ }^{21}$ SPR measurements, ${ }^{21}$ and tdDCC experiments ${ }^{21}$ were conducted as previously described. UV-HPLC analysis of libraries: Column: Waters Altlantis T3, $3 \mu \mathrm{m}, 2.1 \times 150 \mathrm{~mm}$ (Waters Corporation), solvent $\mathrm{A}: \mathrm{H}_{2} \mathrm{O}+0.01 \%$ TFA (trifluoroacetic acid); solvent $\mathrm{B}: \mathrm{MeCN}+0.01 \%$ TFA. Detection: UV absorption at $310 \mathrm{~nm}$. Gradient: $5 \% \rightarrow 25 \%$ B (35 min) $\rightarrow 50 \%$ B (65 min), flow rate: $0.3 \mathrm{~mL} / \mathrm{min}$, injection volume: $20 \mu \mathrm{L}$.

\section{Synthesis}

General. NMR spectra were recorded on a Bruker Avance DMX-500 (500.1 MHz) spectrometer. Assignment of ${ }^{1} \mathrm{H} N M R$ and ${ }^{13} \mathrm{C}$ NMR spectra was achieved using 2D methods (COSY, HSQC). Chemical shifts are expressed in ppm using residual $\mathrm{CHCl}_{3}, \mathrm{MeOH}$, or DMSO as references. Optical rotations were measured with a PerkinElmer Polarimeter 341 and infrared spectra were measured on a PerkinElmer Spectrum One FT-IR Spectrometer. Electrospray ionization mass spectrometry (ESI-MS) data were obtained on a Waters Micromass ZQ instrument. High resolution (HR)MS analysis were carried out using an Agilent 1100 LC equipped with a photodiode array detector and a Micromass QTOF I equipped with a $4 \mathrm{GHz}$ digital-time converter. Reactions were monitored by thin layer chromatography (TLC) using glass plates coated with silica gel $60 \mathrm{~F}_{254}$ (Merck) and visualized by UV light and/or by charring with a molybdate solution ( $0.02 \mathrm{M}$ solution of ammonium cerium sulfate dihydrate and ammonium molybdate tetrahydrate in aqueous $10 \% \mathrm{H}_{2} \mathrm{SO}_{4}$ ). Medium pressure liquid chromatography (MPLC) separations were carried out on a CombiFlash $\mathrm{R}_{f}$ (Teledyne ISCO, Inc.) with RediSep disposable normal-phase or RP-18 (LiChroprepRP18, Merck) reversed-phase flash columns. Commercially available reagents were purchased from Fluka, Aldrich, Alfa Aesar, Fluorochem, and Apollo. Solvents were purchased from Sigma-Aldrich, Acros Organics, or VWR.

\section{Synthesis of the acylhydrazone library}

General procedure A for acylhydrazone formation. A flask was charged with a magnetic stirrer, then aldehyde $\mathbf{1}^{21}$ and hydrazide $\mathbf{2 a}, \mathbf{c}-\mathbf{e}, \mathbf{g}-\mathbf{h}, \mathbf{j}-\mathrm{t}$ were dissolved in $\mathrm{H}_{2} \mathrm{O} / \mathrm{MeCN}(2 \mathrm{~mL}, 7: 3)$. AcOH (100 $\left.\mu \mathrm{L}\right)$ was added and the mixture was stirred at r.t. for 5-22 h until only product was detected by MS. Then, the mixture was neutralized with $1 \mathrm{M}$ aq. $\mathrm{NaOH}$ and the solvents were removed under reduced pressure. The residue was purified by MPLC 
on RP-18 ( $\mathrm{H}_{2} \mathrm{O} / \mathrm{MeCN}, \mathbf{5 : 9 5}$ to $\left.\mathbf{2 0 : 8 0}\right)$ to give the desired products $\mathbf{3 a , c - e , g - h , j - t . ~ F o r ~ s y n t h e s i s ~ o f ~} \mathbf{3 b}, \mathbf{3} \mathbf{f}, \mathbf{3 i}$ and 3u, please see reference 21 .

Note: Compounds $\mathbf{3 a}, \mathbf{3} \mathbf{d}$, and $\mathbf{3} \mathbf{l}$ were obtained as inseparable mixtures of $E$ - and Z-isomers, with the $E$-isomer most likely representing the bigger fraction due to its sterically more favorable conformation. For further evaluation, we conducted a high temperature NMR measurement $\left(\mathrm{CD}_{3} \mathrm{OD}, 60^{\circ} \mathrm{C}\right)$ with compound $3 \mathrm{I}$, which clearly showed a decreased resolution, suggesting faster conversion of the two isomers. Further, HPLC traces at concentrations similar to the DCC experiments showed only one peak. When the reaction was catalyzed by aniline instead of $\mathrm{AcOH}$, the same $E / Z$-ratio was obtained. Thus, the ratio of isomers is expected to be similar in tdDCC and SPR experiments.

$\mathbf{N}^{\prime}$-[3-Fluoro-4-( $\alpha$-D-mannopyranosyloxy)benzylidene]nicotinohydrazide (3a). Prepared according to general procedure A from aldehyde $1(10 \mathrm{mg}, 33.1 \mu \mathrm{mol})$ and nicotinic hydrazide $(2 \mathrm{a}, 4.5 \mathrm{mg}, 33.1 \mu \mathrm{mol})$. Yield: $8.1 \mathrm{mg}$ (58\%) as an inseparable mixture of $E$ - and Z-isomers (approx. 5:1). NMR data are given for the $E$-conformer. $[\alpha]_{\mathrm{D}}^{20}+129.0$ (c 0.35, MeOH); ${ }^{1} \mathrm{H}$ NMR $\left(500 \mathrm{MHz},\left(\mathrm{CD}_{3}\right)_{2} \mathrm{SO}\right): \delta=3.39-3.54(\mathrm{~m}, 4 \mathrm{H}, \mathrm{H}-4, \mathrm{H}-5, \mathrm{H}-6 \mathrm{a}, \mathrm{H}-6 \mathrm{~b}), 3.60$ (dd, J 3.8, 10.6 Hz, 1H), 3.69 (d, J $7.8 \mathrm{~Hz}, 1 \mathrm{H}, \mathrm{H}-3), 3.88(\mathrm{~s}, 1 \mathrm{H}, \mathrm{H}-2), 4.47(\mathrm{~s}, 1 \mathrm{H}, \mathrm{OH}-4), 4.89(\mathrm{~m}, 2 \mathrm{H}, \mathrm{OH}-3, \mathrm{OH}-$ 6), $5.14(\mathrm{~s}, 1 \mathrm{H}, \mathrm{OH}-2), 5.50(\mathrm{~s}, 1 \mathrm{H}, \mathrm{H}-1), 7.45(\mathrm{t}, J 8.3 \mathrm{~Hz}, 1 \mathrm{H}, \mathrm{Ar}-\mathrm{H}), 7.50(\mathrm{~d}, J 8.6 \mathrm{~Hz}, 1 \mathrm{H}, \mathrm{Ar}-\mathrm{H}), 7.52-7.58(\mathrm{~m}$, $1 \mathrm{H}, \mathrm{Ar}-\mathrm{H}), 7.61(\mathrm{~d}, J 11.9 \mathrm{~Hz}, 1 \mathrm{H}, \mathrm{Ar}-\mathrm{H}), 8.25$ (d, J $7.7 \mathrm{~Hz}, 1 \mathrm{H}, \mathrm{Ar}-\mathrm{H}), 8.38(\mathrm{~s}, 1 \mathrm{H}, H \mathrm{C}=\mathrm{N}), 8.75(\mathrm{~d}, J 4.3 \mathrm{~Hz}, 1 \mathrm{H}, \mathrm{Ar}-$ $\mathrm{H}), 9.06$ (s, 1H, Ar-H), 12.05 (s, 1H, NH); $\left.\left.{ }^{13} \mathrm{C} \mathrm{NMR} \mathrm{(125} \mathrm{MHz,} \mathrm{(CD}\right)_{2} \mathrm{SO}\right): \delta 60.9$ (C-6), 66.5 (C-4), 69.8 (C-2), 70.5 (C-3), 75.5 (C-5), 99.7 (C-1), 113.9 (d, JC,F $20 \mathrm{~Hz}$ ), 118.6, 123.6, 124.3, 129.1 (d, JC,F $6 \mathrm{~Hz}$ ), 129.4, 135.4, 145.4 (d, J J,F $11 \mathrm{~Hz} ; 8 \mathrm{C}, \mathrm{Ar}-\mathrm{C}$ ), 146.9 (d, J J,F $2 \mathrm{~Hz}, \mathrm{HC}=\mathrm{N}$ ), 148.6, 152.1 (2C, Ar-C), 152.5 (d, JC,F $245 \mathrm{~Hz}, \mathrm{Ar}-\mathrm{C}), 161.8$ $(\mathrm{C}=\mathrm{O})$; IR (KBr): v 3429 (vs, OH, NH), 1652 (vs, C=N-NH-C=O) cm ${ }^{-1} ; \mathrm{HRMS}: \mathrm{m} / \mathrm{z}$ : Calcd for $\mathrm{C}_{19} \mathrm{H}_{20} \mathrm{FN}_{3} \mathrm{NaO}_{7}$ $[\mathrm{M}+\mathrm{Na}]^{+}:$444.1183, found: 444.1181 .

(E)-N'-[3-Fluoro-4-( $\alpha$-D-mannopyranosyloxy)benzylidene]-2-methylthiazole-5-carbohydrazide (3c). Prepared according to general procedure A from aldehyde $1(10 \mathrm{mg}, 33.1 \mu \mathrm{mol})$ and 2-methyl-thiazole-4-carboxylic acid hydrazide (2c, $5.2 \mathrm{mg}, 33.1 \mu \mathrm{mol})$. Yield: $8.4 \mathrm{mg}(57 \%)$. $[\alpha]_{\mathrm{D}}^{20}+117.7$ (c $\left.0.24, \mathrm{MeOH}\right) ;{ }^{1} \mathrm{H} \mathrm{NMR}(500 \mathrm{MHz}$, $\left.\left(\mathrm{CD}_{3}\right)_{2} \mathrm{SO}\right): \delta 2.75\left(\mathrm{~s}, 3 \mathrm{H}, \mathrm{CH}_{3}\right), 3.41(\mathrm{~m}, 1 \mathrm{H}, \mathrm{H}-5), 3.44-3.54(\mathrm{~m}, 2 \mathrm{H}, \mathrm{H}-6 \mathrm{a}, \mathrm{H}-4), 3.60(\mathrm{dd}, J 5.7,11.2 \mathrm{~Hz}, 1 \mathrm{H}, \mathrm{H}-$ 6b), $3.88(\mathrm{~s}, 1 \mathrm{H}, \mathrm{H}-3), 3.69(\mathrm{~s}, 1 \mathrm{H}, \mathrm{H}-2), 4.46(\mathrm{t}, J 5.7 \mathrm{~Hz}, 1 \mathrm{H}, \mathrm{OH}-6), 4.82$ (d, J $5.4 \mathrm{~Hz}, 1 \mathrm{H}, \mathrm{OH}-3), 4.87$ (d, J $5.5 \mathrm{~Hz}$, $1 \mathrm{H}, \mathrm{OH}-4), 5.11(\mathrm{~d}, J 3.3 \mathrm{~Hz}, 1 \mathrm{H}, \mathrm{OH}-2), 5.49(\mathrm{~s}, 1 \mathrm{H}, \mathrm{H}-1), 7.38-7.49(\mathrm{~m}, 2 \mathrm{H}, \mathrm{Ar}-\mathrm{H}), 7.55(\mathrm{~d}, J 11.7 \mathrm{~Hz}, 1 \mathrm{H}, \mathrm{Ar}-\mathrm{H})$, $8.29(\mathrm{~s}, 1 \mathrm{H}, \mathrm{Ar}-\mathrm{H}), 8.51(\mathrm{~s}, 1 \mathrm{H}, \mathrm{HC}=\mathrm{N}), 11.79(\mathrm{~s}, 1 \mathrm{H}, \mathrm{NH}) ;{ }^{13} \mathrm{CNMR}\left(125 \mathrm{MHz},\left(\mathrm{CD}_{3}\right)_{2} \mathrm{SO}\right): \delta 18.8\left(\mathrm{CH}_{3}\right), 60.9(\mathrm{C}-6)$, 66.5 (C-4), 69.8 (C-2), 70.6 (C-3), 75.5 (C-5), 99.7 (C-1), 113.7 (d, J J,F $20 \mathrm{~Hz}$ ), 118.6, 124.4 (d, J J,F $2 \mathrm{~Hz}$ ), 125.4, $129.3(\mathrm{~d}, J 7 \mathrm{~Hz}), 145.3$ (d, JC,F $11 \mathrm{~Hz} ; 6 \mathrm{C}, \mathrm{Ar}-\mathrm{C}), 147.1(\mathrm{HC}=\mathrm{N}), 148.3,152.5$ (d, JC,F $245 \mathrm{~Hz}), 156.9(3 \mathrm{C}, \mathrm{Ar}-\mathrm{C})$,

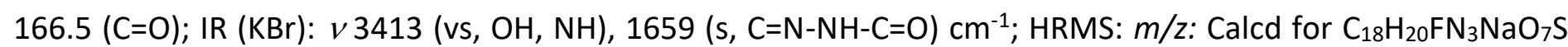
$[\mathrm{M}+\mathrm{Na}]^{+}:$464.0904, found: 464.0905.

$N^{\prime}$-[3-Fluoro-4-( $\alpha$-D-mannopyranosyloxy)benzylidene]-2,4-dimethylthiazole-5-carbohydrazide (3d). Prepared according to general procedure A from aldehyde $1(10 \mathrm{mg}, 33.1 \mu \mathrm{mol})$ and 2,4-dimethyl-thiazole-5-carboxylic acid hydrazide $(\mathbf{2 d}, 5.7 \mathrm{mg}, 33.1 \mu \mathrm{mol})$. Yield: $3.2 \mathrm{mg}(21 \%)$ as a 5:1 mixture of $E$ - and Z-conformer. NMR data are given for the $E$-conformer. $[\alpha]_{\mathrm{D}}^{20}+110.5(c 0.11, \mathrm{MeOH}) ;{ }^{1} \mathrm{H} \mathrm{NMR}\left(500 \mathrm{MHz},\left(\mathrm{CD}_{3}\right)_{2} \mathrm{SO}\right): \delta 2.51,2.66(2 \mathrm{~s}, 6 \mathrm{H}$, $\left.2 \mathrm{CH}_{3}\right), 3.41(\mathrm{~d}, J 7.8 \mathrm{~Hz}, 1 \mathrm{H}, \mathrm{H}-5), 3.43-3.55(\mathrm{~m}, 2 \mathrm{H}, \mathrm{H}-4, \mathrm{H}-6 \mathrm{a}), 3.60$ (dd, J 5.3, $\left.11.1 \mathrm{~Hz}, 1 \mathrm{H}, \mathrm{H}-6 \mathrm{~b}\right), 3.68$ (d, J 8.4 $\mathrm{Hz}, 1 \mathrm{H}, \mathrm{H}-3), 3.88$ (s, 1H, H-2), 4.46 (t, J $5.7 \mathrm{~Hz}, 1 \mathrm{H}, \mathrm{OH}-6), 4.85$ (s, 1H, OH-3), 4.88 (d, J $12.0 \mathrm{~Hz}, 1 \mathrm{H}, \mathrm{OH}-4), 5.13$ (s, 1H, OH-2), 5.49 (s, 1H, H-1), $7.45(\mathrm{~m}, 1 \mathrm{H}, \mathrm{Ar}-\mathrm{H}), 7.50$ (d, J 7.2 Hz, 1H, Ar-H), 7.57 (d, J 11.7 Hz, 1H, Ar-H), 8.02 $(\mathrm{s}, 1 \mathrm{H}, H \mathrm{C}=\mathrm{N}), 11.72(\mathrm{~s}, 1 \mathrm{H}, \mathrm{NH}) ;{ }^{13} \mathrm{CNMR}\left(125 \mathrm{MHz},\left(\mathrm{CD}_{3}\right)_{2} \mathrm{SO}\right): \delta 18.5\left(2 \mathrm{C}, 2 \mathrm{CH}_{3}\right), 60.9(\mathrm{C}-6), 66.5(\mathrm{C}-4), 69.8(\mathrm{C}-$ 2), 70.6 (C-3), 75.5 (C-5), 99.7 (C-1), 114.2 (d, JC,F 19 Hz), 118.8, 124.2 (d, JC,F $3 \mathrm{~Hz}$ ), 128.9, 142.3, 145.2 (d, J J,F $11 \mathrm{~Hz} ; 6 \mathrm{C}, \mathrm{Ar}-\mathrm{C}), 150.5(\mathrm{HC}=\mathrm{N}), 152.4$ (d, J, $\mathrm{F} 245 \mathrm{~Hz}), 160.3,162.2$ (3C, Ar-C), $170.2(\mathrm{C}=\mathrm{O}) ; \mathrm{IR}(\mathrm{KBr}): v 3436$ $(\mathrm{OH}, \mathrm{NH}, \mathrm{vs}), 1646$ (s, C=N-NH-C=O) $\mathrm{cm}^{-1}$; HRMS: m/z: Calcd for $\mathrm{C}_{19} \mathrm{H}_{22} \mathrm{FN}_{3} \mathrm{NaO}_{7} \mathrm{~S}[\mathrm{M}+\mathrm{Na}]^{+}$: 478.1060, found: 478.1061. 

according to general procedure A from aldehyde $1(10 \mathrm{mg}, 33.1 \mu \mathrm{mol})$ and 6-chloropyridine-3-carbohydrazide (2e, $5.7 \mathrm{mg}, 33.1 \mu \mathrm{mol})$. Yield: $3.8 \mathrm{mg}(25 \%)$. $[\alpha]_{\mathrm{D}}^{20}+74.1$ (c 0.30, $\left.\mathrm{MeOH}\right) ;{ }^{1} \mathrm{H} \mathrm{NMR}\left(500 \mathrm{MHz},\left(\mathrm{CD}_{3}\right)_{2} \mathrm{SO}\right): \delta$ 3.38-3.60 (m, 4H, H-6a, H-6b, H-5, H-4), 3.68 (d, J $9.1 \mathrm{~Hz}, 1 \mathrm{H}, \mathrm{H}-3), 3.88$ (s, 1H, H-2), 5.47 (s, 1H, H-1), $7.41(\mathrm{~m}$, $1 \mathrm{H}, \operatorname{Ar}-\mathrm{H}), 7.45$ (d, J $8.6 \mathrm{~Hz}, 1 \mathrm{H}, \mathrm{Ar}-\mathrm{H}), 7.60(\mathrm{~s}, 1 \mathrm{H}, \mathrm{Ar}-\mathrm{H}), 7.62(\mathrm{~d}, J 3.0 \mathrm{~Hz}, 1 \mathrm{H}, \mathrm{Ar}-\mathrm{H}), 8.35(\mathrm{~d}, J 8.3 \mathrm{~Hz}, 1 \mathrm{H}$, $H \mathrm{C}=\mathrm{N}$ ), 8.37 (d, J $9.6 \mathrm{~Hz}, 1 \mathrm{H}, \mathrm{Ar}-\mathrm{H}), 8.93(\mathrm{~s}, 1 \mathrm{H}, \mathrm{Ar}-\mathrm{H}) ;{ }^{13} \mathrm{C} \mathrm{NMR}\left(125 \mathrm{MHz},\left(\mathrm{CD}_{3}\right)_{2} \mathrm{SO}\right): \delta 60.9(\mathrm{C}-6), 66.4(\mathrm{C}-4)$, 69.8 (C-2), 70.5 (C-3), 75.5 (C-5), 99.8 (C-1), 113.7 (d, JC,F 20 Hz), 118.50, 123.8, 124.1, 138.9 (8C, Ar-C), 147.0 $(\mathrm{HC}=\mathrm{N}), 149.3,151.9,152.4$ (d, JC,F $244 \mathrm{~Hz} ; 3 \mathrm{C}, \mathrm{Ar}-\mathrm{C}), 174.0(\mathrm{C}=\mathrm{O})$; IR (KBr): $v 3436$ (vs, OH, NH), 1634 (s, C=N$\mathrm{NH}-\mathrm{C}=\mathrm{O}) \mathrm{cm}^{-1}$; HRMS: $\mathrm{m} / \mathrm{z}$ : Calcd for $\mathrm{C}_{19} \mathrm{H}_{19} \mathrm{ClFN}_{3} \mathrm{NaO}_{7}[\mathrm{M}+\mathrm{Na}]^{+}: 478.0793$, found: 478.0799 .

(E)- $N^{\prime}$-[3-Fluoro-4-( $\alpha$-D-mannopyranosyloxy)benzylidene]-1-methyl-1H-pyrrole-2-carbohydrazide

(3g). Prepared according to general procedure A from aldehyde 1 (10 mg, $33.1 \mu \mathrm{mol}$ ) and 1-methyl-1H-pyrrole-2carboxylic acid hydrazide $(2 \mathrm{~g}, 4.6 \mathrm{mg}, 33.1 \mu \mathrm{mol})$. Yield: $9.5 \mathrm{mg}(68 \%)$. $[\alpha]_{\mathrm{D}}^{20}+132.5(c 0.61, \mathrm{MeOH}) ;{ }^{1} \mathrm{H} \mathrm{NMR}$ (500 MHz, CD $\left.{ }_{3} \mathrm{OD}\right): \delta 3.65(\mathrm{~m}, 1 \mathrm{H}, \mathrm{H}-5), 3.69-3.81(\mathrm{~m}, 3 \mathrm{H}, \mathrm{H}-4, \mathrm{H}-6 \mathrm{a}, \mathrm{H}-6 \mathrm{~b}), 3.93$ (dd, J 3.1, 9.6 Hz, 1H, H-3), $3.96\left(\mathrm{~s}, 3 \mathrm{H}, \mathrm{CH}_{3}\right), 4.08(\mathrm{~s}, 1 \mathrm{H}, \mathrm{H}-2), 5.56(\mathrm{~s}, 1 \mathrm{H}, \mathrm{H}-1), 6.13(\mathrm{~s}, 1 \mathrm{H}, \mathrm{Ar}-\mathrm{H}), 6.93(\mathrm{~s}, 2 \mathrm{H}, \mathrm{Ar}-\mathrm{H}), 7.41(\mathrm{t}, J 8.1 \mathrm{~Hz}, 1 \mathrm{H}$, $\mathrm{Ar}-\mathrm{H}), 7.45(\mathrm{~d}, J 8.6 \mathrm{~Hz}, 1 \mathrm{H}, \mathrm{Ar}-\mathrm{H}), 7.71$ (d, J $11.9 \mathrm{~Hz}, 1 \mathrm{H}, \mathrm{Ar}-\mathrm{H}), 8.15(\mathrm{~s}, 1 \mathrm{H}, \mathrm{HC}=\mathrm{N}) ;{ }^{13} \mathrm{C} \mathrm{NMR}\left(125 \mathrm{MHz}, \mathrm{CD}{ }_{3} \mathrm{OD}\right)$ : $\delta 37.0\left(\mathrm{CH}_{3}\right), 62.6$ (C-6), 68.2 (C-4), 71.8 (C-2), 72.3 (C-3), 76.0 (C-4), $101.2(\mathrm{C}-1), 108.7,115.2\left(\mathrm{~d}, J_{\mathrm{C}, \mathrm{F}} 20 \mathrm{~Hz}\right)$, 119.5, 124.8, 125.7 (d, J $4 \mathrm{~Hz}$ ), 130.7, 131.4 (d, JC,F $7 \mathrm{~Hz} ; 7 \mathrm{C}, \mathrm{Ar}-\mathrm{C}), 146.7$ (d, JC,F $6 \mathrm{~Hz}, \mathrm{HC}=\mathrm{N}), 147.0$ (d, JC,F 11 $\mathrm{Hz}, \mathrm{Ar}-\mathrm{C}$ ), 152.4 (C=O), 154.6 (d, $J_{\mathrm{C}, \mathrm{F}} 246 \mathrm{~Hz}, \mathrm{Ar}-\mathrm{C}$ ); IR (KBr): v 3436 (vs, OH, NH), 1634 (s, C=N-NH-C=O) cm ${ }^{-1}$; HRMS: $m / z$ : Calcd for $\mathrm{C}_{19} \mathrm{H}_{22} \mathrm{FN}_{3} \mathrm{NaO}_{7}[\mathrm{M}+\mathrm{Na}]^{+}:$:446.1339, found: 446.1341 .

(E)-N'-(3-Fluoro-4-( $\alpha$-D-mannopyranosyloxy)benzylidene)-2-methylfuran-3-carbohydrazide (3h). Prepared according to general procedure A from aldehyde $1(10 \mathrm{mg}, 33.1 \mu \mathrm{mol})$ and 2-methyl-furan-carboxylic acid hydrazide $(2 \mathrm{~h}, 4.6 \mathrm{mg}, 33.1 \mu \mathrm{mol})$. Yield: $9.1 \mathrm{mg}(65 \%) .[\alpha]_{\mathrm{D}}^{20}+98.9$ (c 0.56, MeOH); ${ }^{1} \mathrm{H} \mathrm{NMR}(500 \mathrm{MHz}$, $\mathrm{CD}_{3} \mathrm{OD}$ ): $\delta 2.63\left(\mathrm{~s}, 3 \mathrm{H}, \mathrm{CH}_{3}\right), 3.67$ (d, J $\left.3.6 \mathrm{~Hz}, 1 \mathrm{H}, \mathrm{H}-5\right), 3.72-3.83(\mathrm{~m}, 3 \mathrm{H}, \mathrm{H}-4, \mathrm{H}-6 \mathrm{a}, \mathrm{H}-6 \mathrm{~b}), 3.95$ (dd, J $2.8,9.4$ $\mathrm{Hz}, 1 \mathrm{H}, \mathrm{H}-3), 4.10(\mathrm{~s}, 1 \mathrm{H}, \mathrm{H}-2), 5.59$ (s, 1H, H-1), 6.85 (s, 1H, Ar-H), 7.42-7.52 (m, 3H, Ar-H), 7.76 (d, J $11.9 \mathrm{~Hz}$, $1 \mathrm{H}, \mathrm{Ar}-\mathrm{H}$ ), 8.22 (s, $1 \mathrm{H}, \mathrm{HC}=\mathrm{N}) ;{ }^{13} \mathrm{C} \mathrm{NMR}\left(125 \mathrm{MHz}, \mathrm{CD}_{3} \mathrm{OD}\right): \delta 13.7\left(\mathrm{CH}_{3}\right), 62.6$ (C-6), 68.2 (C-4), 71.7 (C-2), 72.3 (C-3), 76.0 (C-5), 101.2 (C-1), 109.4, 115.0, 115.3 (d, $\left.J_{C, F}=20 \mathrm{~Hz}\right), 119.4,126.0,142.1,147.3$ (d, $J_{C, F} 11 \mathrm{~Hz} ; 8 \mathrm{C}$, $\operatorname{Ar}-\mathrm{C}$ ), 147.9 (d, JC,F $1 \mathrm{~Hz}, \mathrm{HC}=\mathrm{N}), 154.6$ (d, JC,F $246 \mathrm{~Hz}$ ), 160.0 (2C, Ar-C), 163.1 (C=O); IR (KBr): $v 3414$ (vs, OH, $\mathrm{NH}$ ), 1619 (vs, $\mathrm{C}=\mathrm{N}-\mathrm{NH}-\mathrm{C}=\mathrm{O}$ ) $\mathrm{cm}^{-1}$; HRMS: $\mathrm{m} / z$ : Calcd for $\mathrm{C}_{19} \mathrm{H}_{21} \mathrm{FN}_{2} \mathrm{Na} \mathrm{O}_{8}[\mathrm{M}+\mathrm{Na}]^{+}$: 447.1182, found: 447.1182.

(E)-N'-[3-Fluoro-4-( $\alpha$-D-mannopyranosyloxy)benzylidene]-4-methoxybenzhydrazide (3j). Prepared according to general procedure A from aldehyde $1(10 \mathrm{mg}, 33.1 \mu \mathrm{mol})$ and 4-methoxybenzhydrazide $(2 \mathrm{j}, 5.5 \mathrm{mg}, 33.1$ $\mu \mathrm{mol})$. Yield: $4.0 \mathrm{mg}(27 \%)$. $[\alpha]_{\mathrm{D}}^{20}+106.6$ (c 0.26, MeOH); ${ }^{1} \mathrm{H}$ NMR $\left(500 \mathrm{MHz}, \mathrm{CD}{ }_{3} \mathrm{OD}\right): \delta 3.64(\mathrm{~m}, 1 \mathrm{H}, \mathrm{H}-5)$, 3.69-3.81 (m, 3H, H-4, H-6a, H-6b), 3.88 (s, 3H, $\mathrm{CH}_{3}$ ), 3.93 (dd, J 3.0, 9.4 Hz, 1H, H-3), 4.08 (s, 1H, H-2), 5.57 (s, $1 \mathrm{H}, \mathrm{H}-1), 7.05$ (d, J $8.5 \mathrm{~Hz}, 2 \mathrm{H}, \mathrm{Ar}-\mathrm{H}), 7.43(\mathrm{t}, J 8.2 \mathrm{~Hz}, 1 \mathrm{H}, \mathrm{Ar}-\mathrm{H}), 7.49(\mathrm{~d}, J 8.5 \mathrm{~Hz}, 1 \mathrm{H}, \mathrm{Ar}-\mathrm{H}), 7.77(\mathrm{~d}, J 11.9 \mathrm{~Hz}$, $1 \mathrm{H}, \mathrm{Ar}-\mathrm{H}), 7.92(\mathrm{~d}, J 8.6 \mathrm{~Hz}, 2 \mathrm{H}, \mathrm{Ar}-\mathrm{H}), 8.25(\mathrm{~s}, 1 \mathrm{H}, \mathrm{HC}=\mathrm{N}) ;{ }^{13} \mathrm{C} \mathrm{NMR}\left(125 \mathrm{MHz}, \mathrm{CD}_{3} \mathrm{OD}\right): \delta 56.0\left(\mathrm{CH}_{3}\right), 62.6(\mathrm{C}-6)$, 68.2 (C-4), 71.7 (C-2), 72.3 (C-3), 76.0 (C-5), 101.2 (C-1), 115.0 (2C), 115.4 (d, J J,F $20 \mathrm{~Hz}$ ), 119.5, 125.96, 126.07 (d, J J,F $2 \mathrm{~Hz} ; 6 \mathrm{C}, \mathrm{Ar}-\mathrm{C}), 130.7(2 \mathrm{C}), 131.1\left(\mathrm{~d}, J_{\mathrm{C}, \mathrm{F}} 7 \mathrm{~Hz}\right), 147.3\left(\mathrm{~d}, J_{C, F} 10 \mathrm{~Hz} ; 4 \mathrm{C}, \mathrm{Ar}-\mathrm{C}\right), 148.4(\mathrm{HC}=\mathrm{N}), 154.6\left(\mathrm{~d}, J_{\mathrm{C}, \mathrm{F}}\right.$

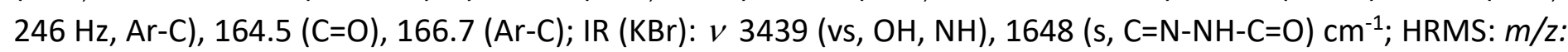
Calcd for $\mathrm{C}_{21} \mathrm{H}_{23} \mathrm{FN}_{2} \mathrm{NaO}_{8}[\mathrm{M}+\mathrm{Na}]^{+}:$473.1336, found: 473.1336 .

(E)- $N^{\prime}$-[3-Fluoro-4-( $\alpha$-D-mannopyranosyloxy)benzylidene]-1H-indole-2-carbohydrazide (3k). Prepared according to general procedure $A$ from aldehyde $1(10 \mathrm{mg}, 33.1 \mu \mathrm{mol})$ and $1 \mathrm{H}$-indole-2-carboxylic acid hydrazide $(2 \mathbf{k}, 5.8 \mathrm{mg}, 33.1 \mu \mathrm{mol})$. Yield: $7.7 \mathrm{mg}(51 \%)$. $[\alpha]_{\mathrm{D}}^{20}+100.9$ (c 0.47, MeOH); ${ }^{1} \mathrm{H} \mathrm{NMR}(500 \mathrm{MHz}$, $\left.\mathrm{CD}_{3} \mathrm{OD}\right): \delta 3.65(\mathrm{~m}, 1 \mathrm{H}, \mathrm{H}-5), 3.70-3.82(\mathrm{~m}, 3 \mathrm{H}, \mathrm{H}-4, \mathrm{H}-6 \mathrm{a}, \mathrm{H}-6 \mathrm{~b}), 3.93(\mathrm{dd}, J 3.0,9.4 \mathrm{~Hz}, 1 \mathrm{H}, \mathrm{H}-3), 4.09(\mathrm{~s}, 1 \mathrm{H}, \mathrm{H}-$ 2), $5.56(\mathrm{~s}, 1 \mathrm{H}, \mathrm{H}-1), 7.15-7.27(\mathrm{~m}, 2 \mathrm{H}, \mathrm{Ar}-\mathrm{H}), 7.38-7.50(\mathrm{~m}, 3 \mathrm{H}, \mathrm{Ar}-\mathrm{H}), 7.73(\mathrm{~s}, 1 \mathrm{H}, \mathrm{Ar}-\mathrm{H}), 8.06(\mathrm{~d}, J 6.4 \mathrm{~Hz}, 1 \mathrm{H}$, 
$\operatorname{Ar}-\mathrm{H}), 8.17(\mathrm{~s}, 1 \mathrm{H}, \mathrm{HC}=\mathrm{N}), 8.22(\mathrm{~d}, \mathrm{~J} 7.1 \mathrm{~Hz}, 1 \mathrm{H}, \mathrm{Ar}-\mathrm{H}) ;{ }^{13} \mathrm{C} N M R\left(125 \mathrm{MHz}, \mathrm{CD}_{3} \mathrm{OD}\right): \delta 62.6$ (C-6), 68.2 (C-4), 71.8 (C-2), 72.3 (C-3), 76.0 (C-5), 101.2 (C-1), 112.8, 115.2 (d, J J,F 19 Hz), 119.5, 122.25, 122.31, 123.9, 125.7, 127.6, 127.7, 129.6, 131.5 (d, JC,F $7 \mathrm{~Hz}$ ), 138.0 (12C, Ar-C), 146.2 (HC=N), 147.0 (d, JC,F $11 \mathrm{~Hz}), 154.6$ (d, JC,F $246 \mathrm{~Hz} ; 2 \mathrm{C}$, Ar-C), 157.3 (C=O); IR (KBr): v 3415 (vs, OH, NH), 1619 (s, C=N-NH-C=O) cm c $^{-1}$ HRMS: m/z: Calcd for $\mathrm{C}_{22} \mathrm{H}_{22} \mathrm{FN}_{3} \mathrm{NaO}_{7}[\mathrm{M}+\mathrm{Na}]^{+}:$482.1339, found: 482.1340 .

$\mathbf{N}^{\prime}$-[3-Fluoro-4-( $\boldsymbol{\alpha}$-D-mannopyranosyloxy)benzylidene]-2-(1H-indol-2-yl)acetohydrazide (3I). Prepared according to general procedure A from aldehyde 1 (10 mg, 33.1 $\mu \mathrm{mol})$ and indole-3-acetic hydrazide (2l, 6.3 $\mathrm{mg}, 33.1 \mu \mathrm{mol})$. Yield: $12.8 \mathrm{mg}(82 \%)$ as a $2: 1$ mixture of $E$ - and $Z$-conformation. $[\alpha]_{\mathrm{D}}^{20}+99.1(c 0.39, \mathrm{MeOH}) ;{ }^{1} \mathrm{H}$ $\mathrm{NMR}\left(500 \mathrm{MHz}, \mathrm{CD}_{3} \mathrm{OD} ; E: Z=2: 1\right.$, normalized to $E$ conformation): $\delta$ 3.61-3.68 (m, $\left.1.5 \mathrm{H}, \mathrm{H}-5 E+Z\right), 3.70-3.81$ $\left(\mathrm{m}, 6.5 \mathrm{H}, \mathrm{CH}_{2} E, \mathrm{H}-6 \mathrm{a} E+Z, \mathrm{H}-6 \mathrm{~b} E+Z, \mathrm{H}-4 E+Z\right), 3.91-3.96(\mathrm{~m}, 1.5 \mathrm{H}, \mathrm{H}-3 E+Z), 4.08(\mathrm{dd}, J 1.9,3.3 \mathrm{~Hz}, 1 \mathrm{H}, \mathrm{H}-2 \mathrm{E})$, 4.10 (dd, J 1.9, 3.4 Hz, 0.5H, H-3 Z), 4.20 (s, 1H, CH Z), $5.57(\mathrm{~d}, J 1.6 \mathrm{~Hz}, 1 \mathrm{H}, \mathrm{H}-1 \mathrm{E}), 5.58(\mathrm{~d}, J 1.6 \mathrm{~Hz}, 0.5 \mathrm{H}, \mathrm{H}-1$ Z), 6.99-7.07 (m, 2H, Ar-H E+Z), 7.08-7.15 (m, 1.5H, Ar-H E+Z), 7.21 (s, 0.5H, Ar-H Z), 7.25 (s, 1H, Ar-H E), 7.47$7.33(\mathrm{~m}, 4.5 \mathrm{H}, 3 \mathrm{Ar}-\mathrm{H}$ E, $3 \mathrm{Ar}-\mathrm{H}$ Z), 7.57 (d, J $12.6 \mathrm{~Hz}, 0.5 \mathrm{H}, \mathrm{Ar}-\mathrm{H}$ Z), 7.61 (d, J 7.9 Hz, 1H, Ar-H E), 7.65 (d, J 8.0 $\mathrm{Hz}, 0.5 \mathrm{H}, \mathrm{Ar}-\mathrm{H}$ Z), 7.70 (dd, J 1.6, $12.0 \mathrm{~Hz}, 1 \mathrm{H}, \mathrm{Ar}-\mathrm{H} E), 7.91(\mathrm{~s}, 0.5 \mathrm{H}, \mathrm{CH}=\mathrm{N} Z), 8.06(\mathrm{~s}, 1 \mathrm{H}, \mathrm{CH}=\mathrm{N} \mathrm{E}) ;{ }^{13} \mathrm{C} \mathrm{NMR}$ (125 MHz, CD $\mathrm{CD}_{3} \mathrm{OD}$; only $E$ conformer): $\delta 32.7\left(\mathrm{CH}_{2}\right), 62.6$ (C-6), 68.2 (C-4), 71.8 (C-2), 72.3 (C-3), 76.0 (C-5), 101.2 (C-1), 126.1, 124.9, 122.6, 122.4, 120.0, 119.4, 115.5, 112.4, 101.4, 148.1 (16 C, $14 \mathrm{Ar}-\mathrm{C}, \mathrm{HC}=\mathrm{N}, \mathrm{C}=\mathrm{O})$; IR $(\mathrm{KBr}): v 3429$ (vs, OH, NH), 1651 (s, C=N-NH-C=O) cm${ }^{-1}$; HRMS: $m / z$ : Calcd for $\mathrm{C}_{23} \mathrm{H}_{24} \mathrm{FN}_{3} \mathrm{NaO}_{7}[\mathrm{M}+\mathrm{Na}]^{+}$: 496.1496 found: 496.1496.

(E)- $N^{\prime}$-[3-Fluoro-4-( $\alpha$-D-mannopyranosyloxy)benzylidene]-4-methylbenzohydrazide (3m). Prepared according to general procedure $A$ from aldehyde $1(10 \mathrm{mg}, 33.1 \mu \mathrm{mol})$ and $p$-toluic hydrazide $(2 \mathrm{~m}, 5.0 \mathrm{mg}, 33.1 \mu \mathrm{mol})$. Yield: $7.7 \mathrm{mg}(54 \%)$. $[\alpha]_{\mathrm{D}}^{20}+104.2$ (c 0.47, MeOH); ${ }^{1} \mathrm{H}$ NMR (500 MHz, CD $\left.{ }_{3} \mathrm{OD}\right): \delta 2.42\left(\mathrm{~s}, 3 \mathrm{H}, \mathrm{CH}_{3}\right), 3.65$ (d, J 5.4 $\mathrm{Hz}, 1 \mathrm{H}, \mathrm{H}-5), 3.70-3.81$ (m, 3H, H-4, H-6a, H-6b), 3.93 (d, J $9.3 \mathrm{~Hz}, 1 \mathrm{H}, \mathrm{H}-3), 4.08$ (s, 1H, H-2), $5.57(\mathrm{~s}, 1 \mathrm{H}, \mathrm{H}-1)$, $7.34(\mathrm{~d}, J 7.8 \mathrm{~Hz}, 2 \mathrm{H}, \mathrm{Ar}-\mathrm{H}), 7.43(\mathrm{t}, J 8.2 \mathrm{~Hz}, 1 \mathrm{H}, \mathrm{Ar}-\mathrm{H}), 7.49(\mathrm{~d}, J 8.5 \mathrm{~Hz}, 1 \mathrm{H}, \mathrm{Ar}-\mathrm{H}), 7.76(\mathrm{~d}, J 11.9 \mathrm{~Hz}, 1 \mathrm{H}, \mathrm{Ar}-\mathrm{H})$, $7.83(\mathrm{~d}, J 7.7 \mathrm{~Hz}, 2 \mathrm{H}, \mathrm{Ar}-\mathrm{H}), 8.25(\mathrm{~s}, 1 \mathrm{H}, \mathrm{HC}=\mathrm{N}) ;{ }^{13} \mathrm{C} \mathrm{NMR}\left(125 \mathrm{MHz}, \mathrm{CD}_{3} \mathrm{OD}\right): \delta 21.5\left(\mathrm{CH}_{3}\right), 62.6(\mathrm{C}-6), 68.2(\mathrm{C}-4)$, 71.7 (C-2), 72.3 (C-3), 76.0 (C-5), 101.2 (C-1), 115.4 (d, J J,F 21 Hz), 119.4, 126.1, $128.8(2 \mathrm{C}), 130.4$ (2C), 131.0 (d, $\left.J_{C, F} 7 \mathrm{~Hz}\right), 131.2,144.3,147.4\left(\mathrm{~d}, J_{C, F} 12 \mathrm{~Hz} ; 11 \mathrm{C}, \mathrm{Ar}-\mathrm{C}\right), 148.8(\mathrm{HC}=\mathrm{N}), 154.6\left(\mathrm{~d}, J_{C, F} 246 \mathrm{~Hz}, \operatorname{Ar}-\mathrm{C}\right), 167.1(\mathrm{C}=\mathrm{O}) ; \mathrm{IR}$ $(\mathrm{KBr}): v 3421$ (vs, OH, NH), 1651 (s, C=N-NH-C=O) cm${ }^{-1} ;$ HRMS: m/z: Calcd for $\mathrm{C}_{21} \mathrm{H}_{23} \mathrm{FN}_{2} \mathrm{NaO}_{7}[\mathrm{M}+\mathrm{Na}]^{+}$: 457.1387, found: 457.1387.

(E)-N'-[3-Fluoro-4-( $\alpha$-D-mannopyranosyloxy)benzylidene]-5-methylthiophene-2-carbohydrazide

$(3 n)$. Prepared according to general procedure A from aldehyde 1 (10 mg, $33.1 \mu \mathrm{mol})$ and 5-methyl-thiophene-2carboxylic acid hydrazide $(2 \mathrm{n}, 5.2 \mathrm{mg}, 33.1 \mu \mathrm{mol})$. Yield: $7.8 \mathrm{mg}(54 \%)$. $[\alpha]_{\mathrm{D}}^{20}+156.0\left(\mathrm{c} \mathrm{0.47,} \mathrm{MeOH);}{ }^{1} \mathrm{H} \mathrm{NMR}\right.$ (500 MHz, $\left.\left(\mathrm{CD}_{3}\right)_{2} \mathrm{SO}\right): \delta 2.52\left(\mathrm{~s}, 3 \mathrm{H}, \mathrm{CH}_{3}\right), 3.39-3.55(\mathrm{~m}, 3 \mathrm{H}, \mathrm{H}-4, \mathrm{H}-5, \mathrm{H}-6 \mathrm{a}), 3.60$ (dd, J 4.9, 10.9 Hz, 1H, H-6b), $3.69(\mathrm{~d}, J 8.9 \mathrm{~Hz}, 1 \mathrm{H}, \mathrm{H}-3), 3.88(\mathrm{~s}, 1 \mathrm{H}, \mathrm{H}-2), 4.46(\mathrm{t}, J 5.8 \mathrm{~Hz}, 1 \mathrm{H}, \mathrm{OH}-6), 4.83(\mathrm{~d}, J 3.6 \mathrm{~Hz}, 1 \mathrm{H}, \mathrm{OH}-3), 4.87(\mathrm{t}, J$ $8.4 \mathrm{~Hz}, 1 \mathrm{H}, \mathrm{OH}-4), 5.12(\mathrm{~d}, J 3.0 \mathrm{~Hz}, 1 \mathrm{H}, \mathrm{OH}-2), 5.50(\mathrm{~s}, 1 \mathrm{H}, \mathrm{H}-1), 6.92(\mathrm{~s}, 1 \mathrm{H}, \mathrm{Ar}-\mathrm{H}), 7.39-7.66(\mathrm{~m}, 3 \mathrm{H}, \mathrm{Ar}-\mathrm{H})$, $7.78(\mathrm{~m}, 1 \mathrm{H}, \mathrm{Ar}-\mathrm{H}), 8.18(\mathrm{~s}, 1 \mathrm{H}, \mathrm{HC}=\mathrm{N}), 11.75(\mathrm{~s}, 1 \mathrm{H}, \mathrm{NH}) ;{ }^{13} \mathrm{C} \mathrm{NMR}\left(125 \mathrm{MHz},\left(\mathrm{CD}_{3}\right)_{2} \mathrm{SO}\right): \delta 15.1\left(\mathrm{CH}_{3}\right), 60.9(\mathrm{C}-6)$, 66.5 (C-5), 69.9 (C-2), 70.6 (C-3), 75.5 (C-4), 99.7 (C-1), 114.03 (d, J J,F 38 Hz), 118.8, 124.2, 125.4, 129.2, 135.1, 142.5, 145.49 (d, JC,F $79 \mathrm{~Hz}), 152.5$ (d, JC,F $245 \mathrm{~Hz}), 161.2$ (11C, $10 \mathrm{Ar}-\mathrm{C}, \mathrm{HC}=\mathrm{N}), 166.4(\mathrm{C}=\mathrm{O}) ; \mathrm{IR}(\mathrm{KBr}): v 3413$ (vs, OH, NH), 1619 (vs, C=N-NH-C=O) $\mathrm{cm}^{-1}$; HRMS: $m / z$ : Calcd for $\mathrm{C}_{19} \mathrm{H}_{21} \mathrm{FN}_{2} \mathrm{NaO}_{7} \mathrm{~S}[\mathrm{M}+\mathrm{Na}]^{+}$: 463.0951, found: 463.0954.

(E)-4-Chloro-N'-[3-fluoro-4-( $\alpha$-D-mannopyranosyloxy)benzylidene]-carbohydrazide (3o). Prepared according to general procedure A from aldehyde $1(10 \mathrm{mg}, 33.1 \mu \mathrm{mol})$ and 4-chlorobenzhydrazide $(20,5.6 \mathrm{mg}, 33.1$ $\mu \mathrm{mol})$. Yield: $4.5 \mathrm{mg}(30 \%)$. $[\alpha]_{\mathrm{D}}^{20}+112.4$ (c 0.24, MeOH); ${ }^{1} \mathrm{H}$ NMR $\left(500 \mathrm{MHz}, \mathrm{CD}_{3} \mathrm{OD}\right): \delta=3.63$ (ddd, $J 2.2,5.3$, $9.5 \mathrm{~Hz}, 1 \mathrm{H}, \mathrm{H}-5$ ), 3.69-3.82 (m, 3H, H-4, H6a, H-6b), 3.93 (dd, J 3.4, 9.4 Hz, 1H, H-3), 4.08 (dd, J 1.7, 3.1 Hz, 1H, $\mathrm{H}-2), 5.57(\mathrm{~s}, 1 \mathrm{H}, \mathrm{H}-1), 7.44(\mathrm{t}, J 8.3 \mathrm{~Hz}, 1 \mathrm{H}, \mathrm{Ar}-\mathrm{H}), 7.50(\mathrm{~d}, J 9.2 \mathrm{~Hz}, 1 \mathrm{H}, \mathrm{Ar}-\mathrm{H}), 7.54(\mathrm{~d}, J 8.5 \mathrm{~Hz}, 2 \mathrm{H}, \mathrm{Ar}-\mathrm{H}), 7.76$ 
(m, 1H, Ar-H), 7.92 (d, J $8.5 \mathrm{~Hz}, 2 \mathrm{H}, \mathrm{Ar}-\mathrm{H}), 8.26(\mathrm{~s}, 1 \mathrm{H}, \mathrm{HC}=\mathrm{N}) ;{ }^{13} \mathrm{C} \mathrm{NMR}\left(125 \mathrm{MHz}, \mathrm{CD}{ }_{3} \mathrm{OD}\right): \delta 62.6$ (C-6), $68.2(\mathrm{C}-$ 4), 71.7 (C-2), 72.3 (C-3), 76.0 (C-5), 101.1 (C-1), 115.5 (d, JC,F 20 Hz), 119.4, 126.2, 130.0 (2C), 130.5 (2C), 130.8 (d, $\left.J_{C, F} 7 \mathrm{~Hz}\right), 132.8,139.5,147.5\left(\mathrm{~d}, J_{\mathrm{C}, \mathrm{F}} 11 \mathrm{~Hz} ; 11 \mathrm{C}, \mathrm{Ar}-\mathrm{C}\right), 149.3(\mathrm{HC}=\mathrm{N}), 154.6\left(\mathrm{~d}, J_{\mathrm{C}, \mathrm{F}} 246 \mathrm{~Hz}, \mathrm{Ar}-\mathrm{C}\right), 165.9$ $(\mathrm{C}=\mathrm{O})$; IR (KBr): $v 3436$ (vs, OH, NH), 1651 (s, C=N-NH-C=O) cm ${ }^{-1}$; HRMS: m/z: Calcd for $\mathrm{C}_{20} \mathrm{H}_{20} \mathrm{ClFN}_{2} \mathrm{NaO}_{7}$ $[\mathrm{M}+\mathrm{Na}]^{+}:$477.0841, found: 477.0841 .

(E)-3-Chloro- $N$ '-[(3-fluoro-4-( $\alpha$-D-mannopyranosyloxy)benzylidene]-4-methylthiophene-2-carbohydrazide

(3p). Prepared according to general procedure A from aldehyde 1 (10 mg, $33.1 \mu \mathrm{mol}$ ) and 3-chloro-4-methyl-2thiophenecarboxylic acid hydrazide $(2 \mathrm{p}, 6.3 \mathrm{mg}, 33.1 \mu \mathrm{mol})$. Yield: $5.4 \mathrm{mg}(34 \%)$. $[\alpha]_{\mathrm{D}}^{20}+90.7(c 0.15, \mathrm{MeOH})$; ${ }^{1} \mathrm{H} \mathrm{NMR}\left(500 \mathrm{MHz},\left(\mathrm{CD}_{3}\right)_{2} \mathrm{SO}\right): \delta 2.20\left(\mathrm{~s}, 3 \mathrm{H}, \mathrm{CH}_{3}\right), 3.37-3.55(\mathrm{~m}, 3 \mathrm{H}, \mathrm{H}-6 \mathrm{a}, \mathrm{H}-4, \mathrm{H}-5), 3.60(\mathrm{dd}, J 3.6,11.2 \mathrm{~Hz}, 1 \mathrm{H}$, $\mathrm{H}-6 \mathrm{~b}), 3.68$ (dd, J 2.9, $9.0 \mathrm{~Hz}, 1 \mathrm{H}, \mathrm{H}-3$ ), 3.87 (s, 1H, H-2), 4.47 (s, 1H, OH-6), 4.90 (s, 2H, OH-3, OH-4), 5.13 (s, $1 \mathrm{H}, \mathrm{OH}-2), 5.49(\mathrm{~s}, 1 \mathrm{H}, \mathrm{H}-1), 7.40-7.48(\mathrm{~m}, 2 \mathrm{H}, \mathrm{Ar}-\mathrm{H}), 7.56(\mathrm{~d}, J 11.9 \mathrm{~Hz}, 1 \mathrm{H}, \mathrm{Ar}-\mathrm{H}), 7.65(\mathrm{~m}, 1 \mathrm{H}, \mathrm{Ar}-\mathrm{H}), 8.06(\mathrm{~m}$, $1 \mathrm{H}, \mathrm{Ar}-\mathrm{H}), 11.77$ (s, $1 \mathrm{H}, \mathrm{NH}) ;{ }^{13} \mathrm{C} \mathrm{NMR}\left(125 \mathrm{MHz},\left(\mathrm{CD}_{3}\right)_{2} \mathrm{SO}\right): \delta 14.3\left(\mathrm{CH}_{3}\right), 60.9$ (C-6), 66.5 (C-4), 69.8 (C-2), 70.5 (C-3), 75.5 (C-5), 99.7 (C-1), 113.9 (d, JC,F 20 Hz), 118.6 (d, JC,F $6 \mathrm{~Hz}$ ), 124.3, 129.1, 131.2, 136.6, 143.6, 143.8 (d, $\left.J_{C, F} 9 \mathrm{~Hz}\right), 145.3(9 \mathrm{C}, \mathrm{Ar}-\mathrm{C}), 146.8(\mathrm{HC}=\mathrm{N}), 152.4$ (d, $\left.J_{\mathrm{C}, \mathrm{F}}=245 \mathrm{~Hz}, \mathrm{Ar}-\mathrm{C}\right), 171.2(\mathrm{C}=\mathrm{O})$; IR (KBr): $v 3430$ (vs, OH, $\mathrm{NH}$ ), 1642 (s, C=N-NH-C=O) $\mathrm{cm}^{-1}$; HRMS: $\mathrm{m} / \mathrm{z}$ : Calcd for $\mathrm{C}_{19} \mathrm{H}_{20} \mathrm{ClFN}_{2} \mathrm{NaO}_{7} \mathrm{~S}[\mathrm{M}+\mathrm{Na}]^{+}$: 497.0561, found: 497.0561.

(E)-5-Chloro- $N^{\prime}$-[3-fluoro-4-( $\alpha$-D-mannopyranosyloxy)benzylidene]-thiophene-2-carbohydrazide

Prepared according to general procedure A from aldehyde 1 (10 mg, $33.1 \mu \mathrm{mol})$ and 5-chlorothiophene-2carboxylic acid hydrazide $(2 \mathbf{2 q}, 5.6 \mathrm{mg}, 33.1 \mu \mathrm{mol})$. Yield: $3.9 \mathrm{mg}(26 \%)$. $[\alpha]_{\mathrm{D}}^{20}+138.3(c \mathrm{0.15}, \mathrm{MeOH}) ;{ }^{1} \mathrm{H} \mathrm{NMR}$ (500 MHz, (CD $)_{2} \mathrm{SO}$ ): $\delta 3.40-3.56$ (m, 3H, H-4, H-5, H-6a), 3.62 (dd, J 4.1, 11.2 Hz, 1H, H-6b), 3.70 (dd, J 3.0, 9.1 $\mathrm{Hz}, 1 \mathrm{H}, \mathrm{H}-3), 3.90$ (s, 1H, H-2), 4.49 (t, J $5.6 \mathrm{~Hz}, 1 \mathrm{H}, \mathrm{OH}-4), 4.89$ (m, 2H, OH-3, OH-6), 5.15 (s, 1H, OH-2), 5.53 (s, $1 \mathrm{H}, \mathrm{H}-1), 7.29$ (d, J $4.1 \mathrm{~Hz}, 1 \mathrm{H}, \mathrm{Ar}-\mathrm{H}), 7.43-7.69(\mathrm{~m}, 3 \mathrm{H}, \mathrm{Ar}-\mathrm{H}), 8.39(\mathrm{~m}, 2 \mathrm{H}, \mathrm{Ar}-\mathrm{H}, \mathrm{HC}=\mathrm{N}), 12.00(\mathrm{~s}, 1 \mathrm{H}, \mathrm{NH}) ;{ }^{13} \mathrm{C}$ NMR (125 MHz, (CD $\left.)_{2} \mathrm{SO}\right): \delta 61.0$ (C-6), 66.5 (C-5), 69.8 (C-2), 70.5 (C-3), 75.5 (C-4), 99.7 (C-1), 114.4 (d, JC,F 19 $\mathrm{Hz}), 118.8,124.4,126.6,128.6\left(\mathrm{~d}, J_{\mathrm{C}, \mathrm{F}} 6 \mathrm{~Hz}\right), 130.4,134.5,137.3(8 \mathrm{C}, \mathrm{Ar}-\mathrm{C}), 143.5(\mathrm{HC}=\mathrm{N}), 145.4\left(\mathrm{~d}, J_{\mathrm{C}, \mathrm{F}} 11 \mathrm{~Hz}\right)$, 152.4 (d, JC,F $245 \mathrm{~Hz} ; 2 \mathrm{C}, \mathrm{Ar}-\mathrm{C}$ ), 160.0 (C=O); IR (KBr): v 3436 (vs, OH, NH), 1651 (s, C=N-NH-C=O) cm-1; HRMS: $\mathrm{m} / \mathrm{z}$ : Calcd for $\mathrm{C}_{18} \mathrm{H}_{18} \mathrm{ClFN}_{2} \mathrm{NaO}_{7} \mathrm{~S}[\mathrm{M}+\mathrm{Na}]^{+}:$483.0405, found: 483.0406 .

(E)-N'-[3-Fluoro-4-( $\alpha$-D-mannopyranosyloxy)benzylidene]-2-naphthohydrazide (3r). Prepared according to general procedure A from aldehyde $1(10 \mathrm{mg}, 33.1 \mu \mathrm{mol})$ and 2-naphthhydrazide $(2 \mathrm{r}, 6.2 \mathrm{mg}, 33.1 \mu \mathrm{mol})$. Yield: $3.9 \mathrm{mg}(25 \%)$. $[\alpha]_{\mathrm{D}}^{20}+81.6$ (c 0.16, MeOH); ${ }^{1} \mathrm{H}$ NMR (500 MHz, CD $\left.{ }_{3} \mathrm{OD}\right): \delta 3.65(\mathrm{~m}, 1 \mathrm{H}, \mathrm{H}-5), 3.69-3.82(\mathrm{~m}$, $3 \mathrm{H}, \mathrm{H}-4, \mathrm{H}-6 \mathrm{a}, \mathrm{H}-6 \mathrm{~b}), 3.93$ (dd, J 2.1, $9.4 \mathrm{~Hz}, 1 \mathrm{H}, \mathrm{H}-3), 4.09$ (s, 1H, H-2), 5.58 (s, 1H, H-1), 7.45 (t, J 8.2 Hz, 1H, $\operatorname{Ar}-\mathrm{H}), 7.53(\mathrm{~d}, J 8.5 \mathrm{~Hz}, 1 \mathrm{H}, \mathrm{Ar}-\mathrm{H}), 7.57-7.66(\mathrm{~m}, 2 \mathrm{H}, \mathrm{Ar}-\mathrm{H}), 7.80(\mathrm{~d}, J 11.9 \mathrm{~Hz}, 1 \mathrm{H}, \mathrm{Ar}-\mathrm{H}), 7.94-8.06(\mathrm{~m}, 4 \mathrm{H}, \mathrm{Ar}-$ $\mathrm{H}), 8.32(\mathrm{~s}, 1 \mathrm{H}, \mathrm{HC}=\mathrm{N}), 8.50(\mathrm{~s}, 1 \mathrm{H}, \mathrm{Ar}-\mathrm{H}) ;{ }^{13} \mathrm{C} \mathrm{NMR}\left(125 \mathrm{MHz}, \mathrm{CD}_{3} \mathrm{OD}\right): \delta 62.6$ (C-6), $68.2(\mathrm{C}-4), 71.8(\mathrm{C}-2), 72.3$ (C-3), 76.1 (C-5), 101.2 (C-1), 115.5 (d, $\left.J_{C, F}=20 \mathrm{~Hz}\right), 119.5,125.0,126.2,128.1,128.9,129.2,129.5,129.6$, 130.1, 131.0 (d, JC,F $7 \mathrm{~Hz}), 131.3,134.0,136.6,147.5$ (d, JC,F $11 \mathrm{~Hz} ; 15 \mathrm{C}, \mathrm{Ar}-\mathrm{C}), 149.0$ (HC=N), 154.6 (d, JC,F 246 $\mathrm{Hz}, \mathrm{Ar}-\mathrm{C}), 167.1(\mathrm{C}=\mathrm{O})$; IR $(\mathrm{KBr}): v 3422$ (vs, OH, NH), 1651 (s, C=N-NH-C=O) cm${ }^{-1}$; HRMS: m/z: Calcd for $\mathrm{C}_{24} \mathrm{H}_{23} \mathrm{FN}_{2} \mathrm{NaO}_{7}[\mathrm{M}+\mathrm{Na}]^{+}: 493.1387$ found: 493.1388.

(E)-N'-[3-Fluoro-4-( $\alpha$-D-mannopyranosyloxy)benzylidene]-4-(trifluoromethyl)benzo-hydrazide (3s). Prepared according to general procedure A from aldehyde $1(10 \mathrm{mg}, 33.1 \mu \mathrm{mol})$ and 4-(trifluoromethyl)benzhydrazide (2s, $6.8 \mathrm{mg}, 33.1 \mu \mathrm{mol})$. Yield: $8.6 \mathrm{mg}(53 \%) .[\alpha]_{\mathrm{D}}^{20}+98.8$ (c 0.39, MeOH); ${ }^{1} \mathrm{H}$ NMR $\left(500 \mathrm{MHz}, \mathrm{CD}_{3} \mathrm{OD}\right): \delta 3.64(\mathrm{~d}$, J $6.2 \mathrm{~Hz}, 1 \mathrm{H}, \mathrm{H}-5), 3.69-3.81(\mathrm{~m}, 3 \mathrm{H}, \mathrm{H}-4, \mathrm{H}-6 \mathrm{a}, \mathrm{H}-6 \mathrm{~b}), 3.93$ (dd, J 2.2, $9.3 \mathrm{~Hz}, 1 \mathrm{H}, \mathrm{H}-3), 4.08(\mathrm{~s}, 1 \mathrm{H}, \mathrm{H}-2), 5.58(\mathrm{~s}$, $1 \mathrm{H}, \mathrm{H}-1), 7.45(\mathrm{t}, J 8.2 \mathrm{~Hz}, 1 \mathrm{H}, \mathrm{Ar}-\mathrm{H}), 7.51(\mathrm{~d}, J 8.5 \mathrm{~Hz}, 1 \mathrm{H}, \mathrm{Ar}-\mathrm{H}), 7.77(\mathrm{~d}, J 11.8 \mathrm{~Hz}, 1 \mathrm{H}, \mathrm{Ar}-\mathrm{H}), 7.84(\mathrm{~d}, J 8.0 \mathrm{~Hz}$, $2 \mathrm{H}, \mathrm{Ar}-\mathrm{H}), 8.10(\mathrm{~d}, J 8.0 \mathrm{~Hz}, 2 \mathrm{H}, \mathrm{Ar}-\mathrm{H}), 8.28(\mathrm{~s}, 1 \mathrm{H}, \mathrm{HC}=\mathrm{N}) ;{ }^{13} \mathrm{C}$ NMR (125 MHz, CD $\left.{ }_{3} \mathrm{OD}\right): \delta 62.6(\mathrm{C}-6), 68.2(\mathrm{C}-4)$, 71.7 (C-2), 72.3 (C-3), 76.1 (C-5), 101.1 (C-1), 115.5 (d, J J,F $20 \mathrm{~Hz}), 119.4(2 \mathrm{C}, \mathrm{Ar}-\mathrm{C}), 125.2$ (q, JC,F $\left.267 \mathrm{~Hz}, \mathrm{CF}_{3}\right)$, $126.3(d, J 3 \mathrm{~Hz}), 126.7(q, J 3 \mathrm{~Hz}, 2 \mathrm{C}), 129.6(2 \mathrm{C}), 130.7$ (d, JC,F $7 \mathrm{~Hz}), 134.6\left(q, J_{C, F} 33 \mathrm{~Hz}\right), 137.9,147.6\left(d, J_{C, F} 11\right.$ 
Hz; 9C, Ar-C), 149.7 (HC=N), 154.6 (d, JC,F 246 Hz, Ar-C), 165.6 (C=O); IR (KBr): v 3430 (vs, OH, NH), 1663 (vs, $\mathrm{C}=\mathrm{N}-\mathrm{NH}-\mathrm{C}=\mathrm{O}$ ) $\mathrm{cm}^{-1}$; HRMS: $\mathrm{m} / \mathrm{z}$ : Calcd for $\mathrm{C}_{21} \mathrm{H}_{20} \mathrm{~F}_{4} \mathrm{~N}_{2} \mathrm{NaO}_{7}[\mathrm{M}+\mathrm{Na}]^{+}: 511.1104$ found: 511.1107 .

(E)-4- $N^{\prime}$-[3-Fluoro-4-( $\alpha$-D-mannopyranosyloxy)benzylidene]benzo[ $b$ ]thiophene-2-carbohydrazide

Prepared according to general procedure A from aldehyde 1 (10 mg, $33.1 \mu \mathrm{mol}$ ) and 3-chlorobenzo[b]thiophene acid hydrazide $(2 \mathrm{t}, 7.5 \mathrm{mg}, 33.1 \mu \mathrm{mol})$. Yield: $4.2 \mathrm{mg}(25 \%)$. $[\alpha]_{\mathrm{D}}^{20}+82.4(c 0.18, \mathrm{MeOH}) ;{ }^{1} \mathrm{H}$ NMR $\left(500 \mathrm{MHz},\left(\mathrm{CD}_{3}\right)_{2} \mathrm{SO}\right): \delta 3.38-3.51(\mathrm{~m}, 3 \mathrm{H}, \mathrm{H}-6 \mathrm{a}, \mathrm{H}-6 \mathrm{~b}, \mathrm{H}-5), 3.59(\mathrm{~s}, 1 \mathrm{H}, \mathrm{H}-4), 3.68(\mathrm{~s}, 1 \mathrm{H}, \mathrm{H}-3), 3.88(\mathrm{~s}, 1 \mathrm{H}$, $\mathrm{H}-2), 4.47$ (s, 1H, OH-4), 4.71-4.96 (m, 2H, OH-3, OH-6), $5.11(\mathrm{~s}, 1 \mathrm{H}, \mathrm{OH}-2), 5.49$ (s, 1H, H-1), 7.35-7.69 (m, 5H, $\mathrm{Ar}-\mathrm{H}), 8.44-8.84(\mathrm{~m}, 3 \mathrm{H}, 2 \mathrm{Ar}-\mathrm{H}, \mathrm{HC}=\mathrm{N}), 12.09(\mathrm{~s}, 1 \mathrm{H}, \mathrm{NH}) ;{ }^{13} \mathrm{C} \mathrm{NMR}\left(125 \mathrm{MHz},\left(\mathrm{CD}_{3}\right){ }_{2} \mathrm{SO}\right): \delta 60.9$ (C-6), $66.5(\mathrm{C}-$ 4), 69.8 (C-2), 70.5 (C-3), 75.5 (C-5), 99.8 (C-1), 114.2 (d, J J,F 20 Hz), 118.6, 122.4, 122.6, 123.4, 124.4, 126.0, 127.4, 127.7, 132.6, 143.5, 145.4, 147.5, 152.5 (d, JC,F 245 Hz; 15C, Ar-C, HC=N), $160.2(\mathrm{C}=\mathrm{O}) ; \mathrm{IR}(\mathrm{KBr}): v 3460$ (vs, OH, NH), 1656 (vs, C=N-NH-C=O) $\mathrm{cm}^{-1} ;$ HRMS: $\mathrm{m} / z$ : Calcd for $\mathrm{C}_{22} \mathrm{H}_{20} \mathrm{ClFN}_{2} \mathrm{NaO}_{7} \mathrm{~S}[\mathrm{M}+\mathrm{Na}]^{+}: 533.0561$ found: 533.0562.

\section{Synthesis of bioisosteres}

General procedure B for deprotection of acetylated mannosides. Protected mannosides were dissolved in dry $\mathrm{MeOH}(2 \mathrm{~mL})$ under argon atmosphere and freshly prepared $1 \mathrm{M} \mathrm{NaOMe}(100 \mu \mathrm{L})$ was added. The mixtures were stirred at r.t. for 30-45 min, until TLC $\left(\mathrm{CH}_{2} \mathrm{Cl}_{2} / \mathrm{MeOH}, 9: 1\right)$ showed no remaining starting material. The mixtures were neutralized with amberlite ion-exchange resin ( $\mathrm{H}^{+}$-form, IR120, Sigma Aldrich), filtered, and concentrated in vacuo. The residues were purified by MPLC (RP-18; $\mathrm{H}_{2} \mathrm{O} / \mathrm{MeCN}, 95: 5$ to 20:80) to yield 60-82\% of the desired products.
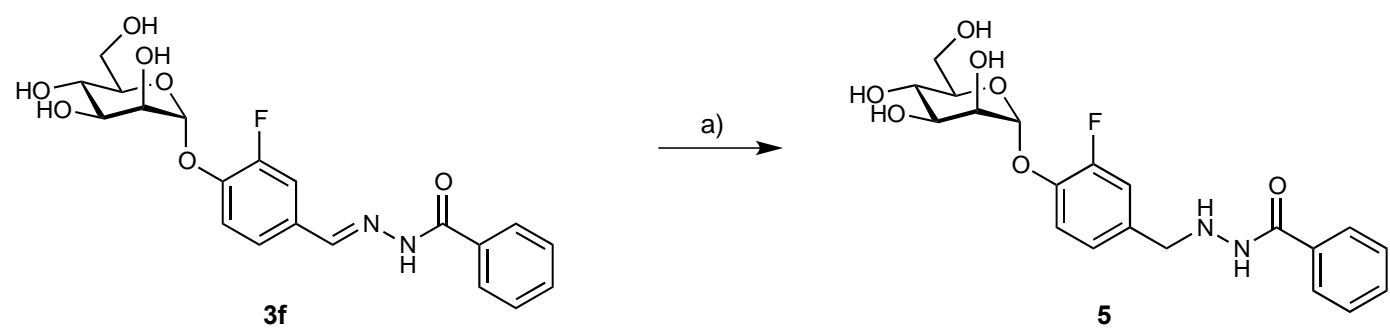

Scheme 2. Reagents and conditions: a) $\mathrm{NaBH}_{3} \mathrm{CN}$, aq. $\mathrm{HCl}$., $\mathrm{MeOH}$, r.t., $23 \mathrm{~h}, 95 \%$.

$\boldsymbol{N}^{\prime}$-[3-Fluoro-4-( $\boldsymbol{\alpha}$-D-mannopyranosyloxy)benzyl]benzohydrazide (5). Compound $3 f(4.5 \mathrm{mg}, 10.7 \mu \mathrm{mol}, 1$ eq.) was dissolved in $\mathrm{MeOH}\left(3 \mathrm{~mL}\right.$ ) and $\mathrm{NaBH}_{3} \mathrm{CN}(6.7 \mathrm{mg}, 107 \mu \mathrm{mol}, 10$ eq.) and five drops of $36 \%$ aq. $\mathrm{HCl}$. were added. The mixture was flushed with argon for $5 \mathrm{~min}$ and stirred at r.t. After $23 \mathrm{~h}$ the mixture was neutralized with solid $\mathrm{NaOH}$ and concentrated. The residue was purified by MPLC on RP-18 ( $\mathrm{H}_{2} \mathrm{O} / \mathrm{MeCN}, 95: 5$ to 20:80) to give 5 (4.3 mg, 95\%). $[\alpha]_{\mathrm{D}}^{20}+66.3$ (c 0.22, MeOH); ${ }^{1} \mathrm{H}$ NMR (500 MHz, CD $\left.{ }_{3} \mathrm{OD}\right): \delta 3.64-3.79(\mathrm{~m}, 4 \mathrm{H}, \mathrm{H}-4, \mathrm{H}-5, \mathrm{H}-$ 6a, H-6b), 3.91 (dd, J 3.4, 9.3 Hz, 1H, H-3), 4.00 (s, 2H, CH2), 4.06 (dd, J 1.8, 3.3 Hz, 1H, H-2), 5.46 (d, J $1.5 \mathrm{~Hz}$, $1 \mathrm{H}, \mathrm{H}-1), 7.13(\mathrm{~d}, J 8.4 \mathrm{~Hz}, 1 \mathrm{H}, \mathrm{Ar}-\mathrm{H}), 7.24$ (dd, J 1.9, $11.9 \mathrm{~Hz}, 1 \mathrm{H}, \mathrm{Ar}-\mathrm{H}), 7.31(\mathrm{t}, J 8.4 \mathrm{~Hz}, 1 \mathrm{H}, \mathrm{Ar}-\mathrm{H}), 7.42(\mathrm{t}, J 7.5$ $\mathrm{Hz}, 2 \mathrm{H}, \mathrm{Ar}-\mathrm{H}), 7.50(\mathrm{~m}, 1 \mathrm{H}, \mathrm{Ar}-\mathrm{H}), 7.69-7.75(\mathrm{~m}, 2 \mathrm{H}, \mathrm{Ar}-\mathrm{H}) ;{ }^{13} \mathrm{C} N M R\left(125 \mathrm{MHz}, \mathrm{CD}_{3} \mathrm{OD}\right): \delta=55.5\left(\mathrm{CH}_{2}\right), 62.6(\mathrm{C}-$ 6), 68.2 (C-4), 71.9 (C-2), 72.3 (C-3), 75.8 (C-5), 101.6 (C-1), 117.9 (d, J J,F $19 \mathrm{~Hz}$ ), 120.0, 126.2 (d, JC,F 3 Hz), 128.2, 129.5, 132.6, 134.5, $134.8\left(\mathrm{~d}, J_{\mathrm{C}, \mathrm{F}} 17 \mathrm{~Hz}\right), 144.8\left(\mathrm{~d}, J_{\mathrm{C}, \mathrm{F}}=11 \mathrm{~Hz}\right), 154.5$ (d, $\left.J_{\mathrm{C}, \mathrm{F}} 245 \mathrm{~Hz} ; 12 \mathrm{C}, \operatorname{Ar}-\mathrm{C}\right), 169.0$ $(\mathrm{C}=\mathrm{O})$; IR (KBr): $v 3438$ (vs, OH), $1646(\mathrm{~s}, \mathrm{C}=\mathrm{O}) \mathrm{cm}^{-1}$; HRMS: $\mathrm{m} / \mathrm{z}$ : Calcd for $\mathrm{C}_{20} \mathrm{H}_{24} \mathrm{FN}_{2} \mathrm{NaO}_{7}[\mathrm{M}+\mathrm{Na}]^{+}:$445.1387, found: 445.1386 . 

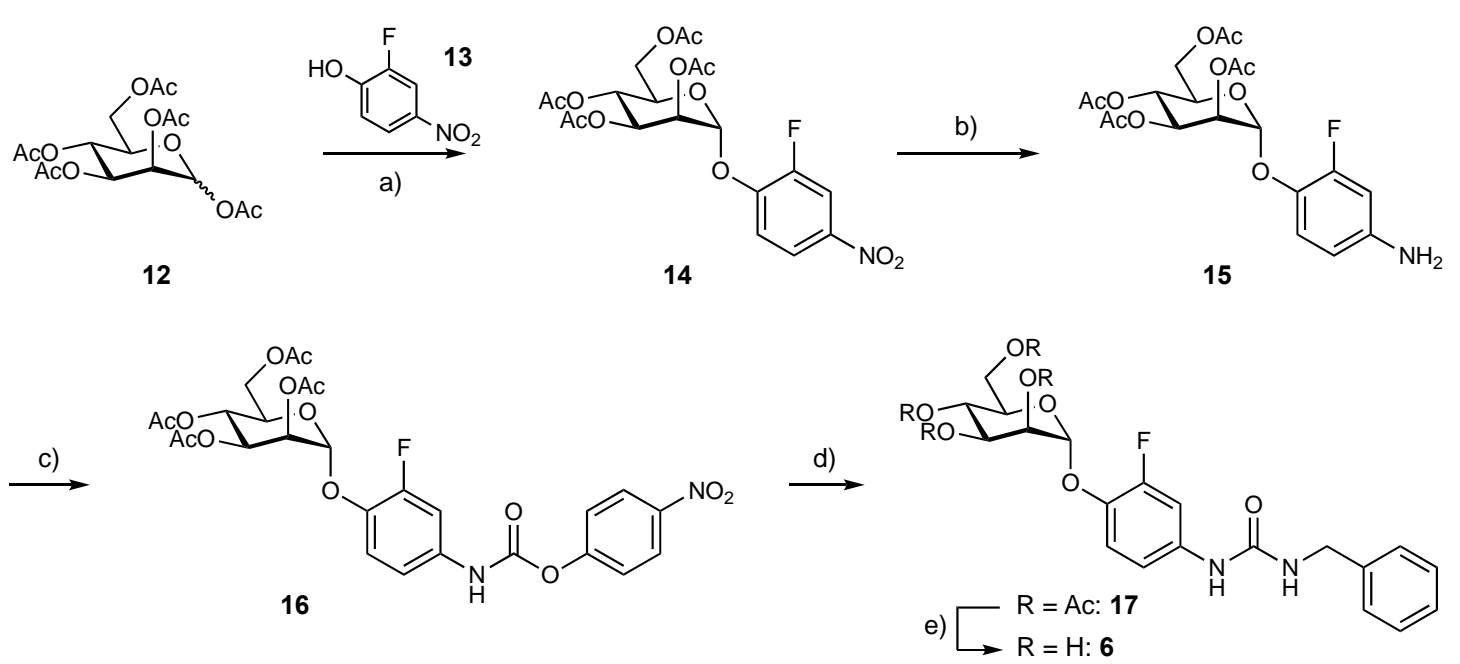

Scheme 3. Reagents and conditions: a) $\mathrm{BF}_{3} \cdot \mathrm{Et}_{2} \mathrm{O}, \mathrm{CH}_{2} \mathrm{Cl}_{2}, \mathrm{MS} 4 \AA$, $50{ }^{\circ} \mathrm{C}, 21 \mathrm{~h}, 39 \%$; b) $\mathrm{H}_{2}, \mathrm{Pd}(\mathrm{OH})_{2}, \mathrm{THF} / \mathrm{MeOH}$ (2:1), r.t., 2h, 75\%; c) 4-nitrophenyl chloroformate, DIPEA, $\mathrm{CH}_{2} \mathrm{Cl}_{2}, 2 \mathrm{~h}$; d) benzylamine, DIPEA, THF, $2.5 \mathrm{~h}$, 29\% (over two steps); e) $\mathrm{NaOMe}, \mathrm{MeOH}$, r.t., $45 \mathrm{~min}, 70 \%$.

2-Fluoro-4-nitrophenyl 2,3,4,6-tetra-O-acetyl- $\alpha$-D-mannopyranoside (14). In a two-necked flask, activated MS $4 \AA ̊$ (ca. $500 \mathrm{mg}$ ), peracetylated D-mannose (12, $500 \mathrm{mg}, 1.28 \mathrm{mmol}, 1.2$ eq.), 3-fluoro-4-nitrophenol (13, 168 $\mathrm{mg}, 1.07 \mathrm{mmol}, 1.0$ eq.), and dry $\mathrm{CH}_{2} \mathrm{Cl}_{2}(10 \mathrm{~mL})$ were mixed and cooled down in an ice bath. Under argon atmosphere, $\mathrm{BF}_{3} \cdot \mathrm{Et}_{2} \mathrm{O}\left(395 \mu \mathrm{L}, 3.20 \mathrm{mmol}, 3.0\right.$ eq.) was added dropwise and the reaction heated to $50{ }^{\circ} \mathrm{C}$. The mixture was refluxed for $21 \mathrm{~h}$. Then it was cooled down to r.t., diluted with EtOAc, and filtered over celite. The filtrate was subsequently washed with satd. aq. $\mathrm{NaHCO}_{3}$ and brine. The organic layer was dried over $\mathrm{Na}_{2} \mathrm{SO}_{4}$, filtered, and concentrated in vacuo. The residue was purified by MPLC on silica (petroleum ether/EtOAc, 1:0 to 4:6) to give 14 (241 mg, 39\%). $[\alpha]_{\mathrm{D}}^{20}+92.8$ (c 1.00, $\left.\mathrm{CHCl}_{3}\right) ;{ }^{1} \mathrm{H} \mathrm{NMR}\left(500 \mathrm{MHz}, \mathrm{CDCl}_{3}\right): \delta 2.03,2.05,2.07,2.22(4$ s, $\left.12 \mathrm{H}, 4 \mathrm{Ac}_{-} \mathrm{CH}_{3}\right), 4.06-4.15(\mathrm{~m}, 2 \mathrm{H}, \mathrm{H}-5, \mathrm{H}-6 \mathrm{a}), 4.27$ (dd, J 5.9, $\left.12.8 \mathrm{~Hz}, 1 \mathrm{H}, \mathrm{H}-6 \mathrm{~b}\right), 5.39(\mathrm{t}, J 9.9 \mathrm{~Hz}, 1 \mathrm{H}, \mathrm{H}-4)$, 5.52 (dd, J 1.8, 3.5 Hz, 1H, H-2), 5.55 (dd, J 3.5, 9.9 Hz, 1H, H-3), 5.65 (d, J $1.5 \mathrm{~Hz}, 1 \mathrm{H}, \mathrm{H}-1), 7.36(\mathrm{~m}, 1 \mathrm{H}, \mathrm{Ar}-\mathrm{H})$,

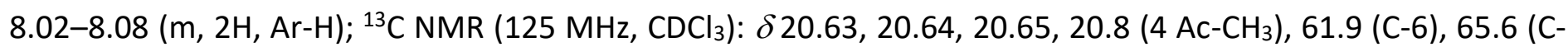
4), 68.4 (C-3), 68.9 (C-2), 70.2 (C-5), 96.9 (C-1), 113.0 (d, JC,F 23 Hz), 117.1 (d, JC,F 1 Hz), 120.5 (d, JC,F 4 Hz), 143.0 (d, $J_{C, F} 7 \mathrm{~Hz}$ ), 148.8 (d, $J_{C, F} 11 \mathrm{~Hz}$ ), 151.9 (d, $J_{C, F} 254$ Hz; 6C, Ar-C), 169.6, 169.8, 169.9, 170.4 (4 C=O); ESI-MS: $\mathrm{m} / \mathrm{z}$ : Calcd for $\mathrm{C}_{20} \mathrm{H}_{22} \mathrm{FNNaO}_{12}[\mathrm{M}+\mathrm{Na}]^{+}:$510.10, found: 510.14 .

4-Amino-2-fluorophenyl 2,3,4,6-tetra-O-acetyl- $\alpha$-D-mannopyranoside (15). A two-necked flask equipped with a magnetic stirrer was charged with $14(241 \mathrm{mg}, 0.527 \mathrm{mmol})$. Under argon atmosphere, THF/MeOH (2:1, 15 $\mathrm{mL}$ ) and $\mathrm{Pd}(\mathrm{OH})_{2} / \mathrm{C}(25 \mathrm{mg})$ were added. The flask was evacuated five times and filled with $\mathrm{H}_{2}$. Under hydrogen atmosphere, the mixture was stirred at r.t. until $\operatorname{TLC}\left(\mathrm{CH}_{2} \mathrm{Cl}_{2} / \mathrm{MeOH}, 8: 2\right)$ indicated completion of the reaction. The mixture was filtered over celite and concentrated. Purification by MPLC (petroleum ether/EtOAc, 1:0 to 0:1) gave 15 (181 mg, 75\%). $[\alpha]_{\mathrm{D}}^{20}+74.5$ (c 2.01, $\left.\mathrm{CHCl}_{3}\right) ;{ }^{1} \mathrm{H} \mathrm{NMR}\left(500 \mathrm{MHz}, \mathrm{CDCl}_{3}\right): \delta 1.97,2.00,2.01,2.12(4 \mathrm{~s}$, $\left.12 \mathrm{H}, 4 \mathrm{Ac}_{-} \mathrm{CH}_{3}\right), 3.71$ (s, 2H, NH ), 4.07 (dd, J 1.8, $\left.12.1 \mathrm{~Hz}, 1 \mathrm{H}, \mathrm{H}-6 \mathrm{a}\right), 4.18-4.28$ (m, 2H, H-5, H-6b), 5.22 (s, 1H, $\mathrm{H}-1), 5.29$ (t, J $9.9 \mathrm{~Hz}, 1 \mathrm{H}, \mathrm{H}-4), 5.44$ (dd, J 1.7, 3.3 Hz, 1H, H-2), 5.47 (dd, J 3.4, 9.9 Hz, 1H, H-3), 6.29 (m, 1H, Ar$\mathrm{H}), 6.37$ (dd, J 2.6, $12.5 \mathrm{~Hz}, 1 \mathrm{H}, \mathrm{Ar}-\mathrm{H}), 6.86(\mathrm{t}, J 8.8 \mathrm{~Hz}, 1 \mathrm{H}, \mathrm{Ar}-\mathrm{H}) ;{ }^{13} \mathrm{C} \mathrm{NMR}\left(125 \mathrm{MHz}, \mathrm{CDCl}_{3}\right): \delta 20.46,20.49$, 20.6 (4C, $4 \mathrm{AC}^{-\mathrm{CH}_{3}}$ ), 62.1 (C-6), 65.8 (C-4), 68.7 (C-3), 69.2 (2C, C-3, C-5), 98.6 (d, JC,F $1 \mathrm{~Hz}, \mathrm{C}-1$ ), 103.3 (d, J J,F 22 $\mathrm{Hz}), 110.2$ (d, JC,F $3 \mathrm{~Hz}$ ), 121.4 (d, JC,F $2 \mathrm{~Hz}$ ), 134.9 (d, JC,F $12 \mathrm{~Hz}$ ), 144.1 (d, JC,F $10 \mathrm{~Hz}$ ), 154.3 (d, JC,F 246 Hz; 6C, ArC), 169.6, 169.7, 169.8, 170.4 (4 C=O); ESI-MS: $m / z$ : Calcd for $\mathrm{C}_{20} \mathrm{H}_{24} \mathrm{FNNaO}_{10}[\mathrm{M}+\mathrm{Na}]^{+}$: 480.13, found: 480.13 . 
4-Nitrophenyl (4'-(2,3,4,6-tetra-O-acetyl- $\alpha$-D-mannopyranosyloxy)-3'-fluorophenyl)carbamate (16). In a two-

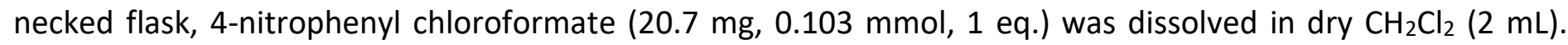
Under argon atmosphere, a solution of 15 (47 mg, $0.103 \mathrm{mmol}, 1$ eq.) and DIPEA (17.6 $\mu \mathrm{L}, 0.103 \mathrm{mmol}, 1$ eq.) in dry $\mathrm{CH}_{2} \mathrm{Cl}_{2}(2 \mathrm{~mL}$ ) was added dropwise. The mixture was stirred at r.t. for $2 \mathrm{~h}$, until TLC (petroleum ether/EtOAc, 1:1) showed completion of the reaction. The mixture was diluted with EtOAc and washed with 1 $\mathrm{M}$ aq. $\mathrm{HCl}$. The organic layer was dried over $\mathrm{Na}_{2} \mathrm{SO}_{4}$, filtered, and concentrated to give 16 (quant.) which was used without further purification. ESI-MS: $m / z$ : Calcd for $\mathrm{C}_{27} \mathrm{H}_{27} \mathrm{FN}_{2} \mathrm{NaO}_{14}[\mathrm{M}+\mathrm{Na}]^{+}$: 645.13, found: 645.16.

1-Benzyl-3-[4'-(2,3,4,6-tetra-O-acetyl- $\alpha$-D-mannopyranosyloxy)-3'-fluorophenyl]urea (17). Crude 16 was dissolved in dry THF $(2 \mathrm{~mL})$ and benzylamine $(11.3 \mathrm{mg}, 0.103 \mathrm{mmol}, 1$ eq.) and DIPEA (17.6 $\mu \mathrm{L}, 0.103 \mathrm{mmol}, 1$ eq.) were added. The reaction was stirred for $1.5 \mathrm{~h}$, until $\mathrm{TLC}\left(\mathrm{CH}_{2} \mathrm{Cl}_{2} / \mathrm{MeOH}, 9: 1\right)$ indicated full consumption of the starting material. The mixture was concentrated, dissolved in EtOAc, washed with $1 \mathrm{M}$ aq. $\mathrm{HCl}$ and the aqueous layer re-extracted with EtOAc (3x). The organic layer was dried over $\mathrm{Na}_{2} \mathrm{SO}_{4}$, filtered and the solvent removed. Purification by MPLC (petroleum ether/EtOAc, 1:0 to 0:1) gave 17 (17.1 mg, 29\% over two steps). $[\alpha]_{\mathrm{D}}^{20}+35.8$ (c 0.89, $\left.\mathrm{CHCl}_{3}\right) ;{ }^{1} \mathrm{H}$ NMR $\left(500 \mathrm{MHz}, \mathrm{CDCl}_{3}\right): \delta 2.01,2.02,2.06,2.18\left(4 \mathrm{~s}, 12 \mathrm{H}, 4 \mathrm{Ac}-\mathrm{CH}_{3}\right), 4.08(\mathrm{dd}, \mathrm{J}$ 3.4, 13.2 Hz, 1H, H-6a), 4.21-4.28 (m, 2H, H-6b, H-5), 4.37 (d, J $\left.5.7 \mathrm{~Hz}, 2 \mathrm{H}, \mathrm{CH}_{2}\right), 5.32-5.38(\mathrm{~m}, 2 \mathrm{H}, \mathrm{H}-4, \mathrm{H}-1)$, $5.41(\mathrm{t}, J 5.6 \mathrm{~Hz}, 1 \mathrm{H}, \mathrm{NH}), 5.49$ (dd, J 1.8, 3.4 Hz, 1H, H-2), 5.52 (dd, J 3.5, $9.9 \mathrm{~Hz}, 1 \mathrm{H}, \mathrm{H}-3$ ), 6.91 (dd, J $1.2,8.9$ $\mathrm{Hz}, 1 \mathrm{H}, \mathrm{Ar}-\mathrm{H}), 6.94(\mathrm{~s}, 1 \mathrm{H}, \mathrm{NH}), 7.00(\mathrm{t}, J 8.8 \mathrm{~Hz}, 1 \mathrm{H}, \mathrm{Ar}-\mathrm{H}), 7.21-7.27(\mathrm{~m}, 4 \mathrm{H}, \mathrm{Ar}-\mathrm{H}), 7.27-7.32(\mathrm{~m}, 2 \mathrm{H}, \mathrm{Ar}-\mathrm{H}) ;{ }^{13} \mathrm{C}$ NMR $\left(125 \mathrm{MHz}, \mathrm{CDCl}_{3}\right): \delta 20.65,20.66,20.8\left(4 \mathrm{C}, 4 \mathrm{Ac}-\mathrm{CH}_{3}\right), 44.2\left(\mathrm{CH}_{2}\right), 62.1$ (C-6), $65.8(\mathrm{C}-3), 68.9$ (C-2), 69.3 (C-4), 69.5 (C-5), 98.1 (C-1), 109.1 (d, J J,F $23 \mathrm{~Hz}$ ), 115.6 (d, J J,F $3 \mathrm{~Hz}$ ), 120.1 (d, J J,F $2 \mathrm{~Hz}$ ), 127.4, 127.5, 128.7, 135.5 (d, JC,F $9 \mathrm{~Hz}$ ), 138.6, 138.8 (d, JC,F $12 \mathrm{~Hz}$ ), 153.5 (d, J J,F $247 \mathrm{~Hz} ; 12 \mathrm{C}$, Ar-C), 155.4 (NC=O), 169.8, 170.0, 170.7 (4C, 4 C=O); ESI-MS: $m / z$ : Calcd for $\mathrm{C}_{28} \mathrm{H}_{31} \mathrm{FN}_{2} \mathrm{Na} \mathrm{O}_{11}[\mathrm{M}+\mathrm{Na}]^{+}$: 613.18, found: 613.22.

1-Benzyl-3-[3'-fluoro-4'-( $\alpha$-D-mannopyranosyloxy)phenyl]urea (6). Prepared according to general procedure B from 17 (17.7 mg, $30.0 \mu \mathrm{mol})$. Yield: $8.8 \mathrm{mg}(70 \%)$. [ $\alpha]_{\mathrm{D}}^{20}+109.9$ (c 0.44, MeOH); ${ }^{1} \mathrm{H} \mathrm{NMR}\left(500 \mathrm{MHz}, \mathrm{CD}{ }_{3} \mathrm{OD}\right)$ : $\delta 3.70-3.81(\mathrm{~m}, 4 \mathrm{H}, \mathrm{H}-4, \mathrm{H}-5, \mathrm{H}-6 \mathrm{a}, \mathrm{H}-6 \mathrm{~b}), 3.90(\mathrm{~m}, 1 \mathrm{H}, \mathrm{H}-3), 4.06$ (dd, J 1.8, 3.3 Hz, 1H, H-2), $4.37\left(\mathrm{~s}, 2 \mathrm{H}, \mathrm{CH}_{2}\right)$, $5.35(\mathrm{~d}, J 1.7 \mathrm{~Hz}, 1 \mathrm{H}, \mathrm{H}-1), 6.95$ (ddd, J 1.3, 2.4, 8.9 Hz, 1H, Ar-H), 7.19-7.27 (m, 2H, Ar-H), 7.29-7.34 (m, 4H, $\mathrm{Ar}-\mathrm{H}$ ), 7.38 (dd, J 2.5, 13.3 Hz, 1H, Ar-H); ${ }^{13} \mathrm{C}$ NMR (125 MHz, CD $3 \mathrm{OD}$ ): $\delta 44.5\left(\mathrm{CH}_{2}\right), 62.7$ (C-6), 68.3 (C-4), 71.9 (C-2), 72.3 (C-3), 75.7 (C-5), 102.3 (C-1), 108.8 (d, J J,F $24 \mathrm{~Hz}$ ), 115.7 (d, J J,F $3 \mathrm{~Hz}$ ), 121.2 (d, JC,F $2 \mathrm{~Hz}), 128.1$, 128.3, 129.6, 137.1 (d, JC,F $10 \mathrm{~Hz}$ ), 140.4 (d, JC,F $11 \mathrm{~Hz}), 140.9,154.7$ (d, JC,F $243 \mathrm{~Hz} ; 12 \mathrm{C}, \operatorname{Ar}-\mathrm{C}), 158.0$ (C=O); IR (KBr): $v 3347$ (vs, OH), 1635 (s, C=O), 1515 (vs, NH) cm ${ }^{-1}$; HRMS: m/z: Calcd for $\mathrm{C}_{20} \mathrm{H}_{24} \mathrm{FN}_{2} \mathrm{NaO}_{7}[\mathrm{M}+\mathrm{Na}]^{+}$: 445.1387, found: 445.1392 . 

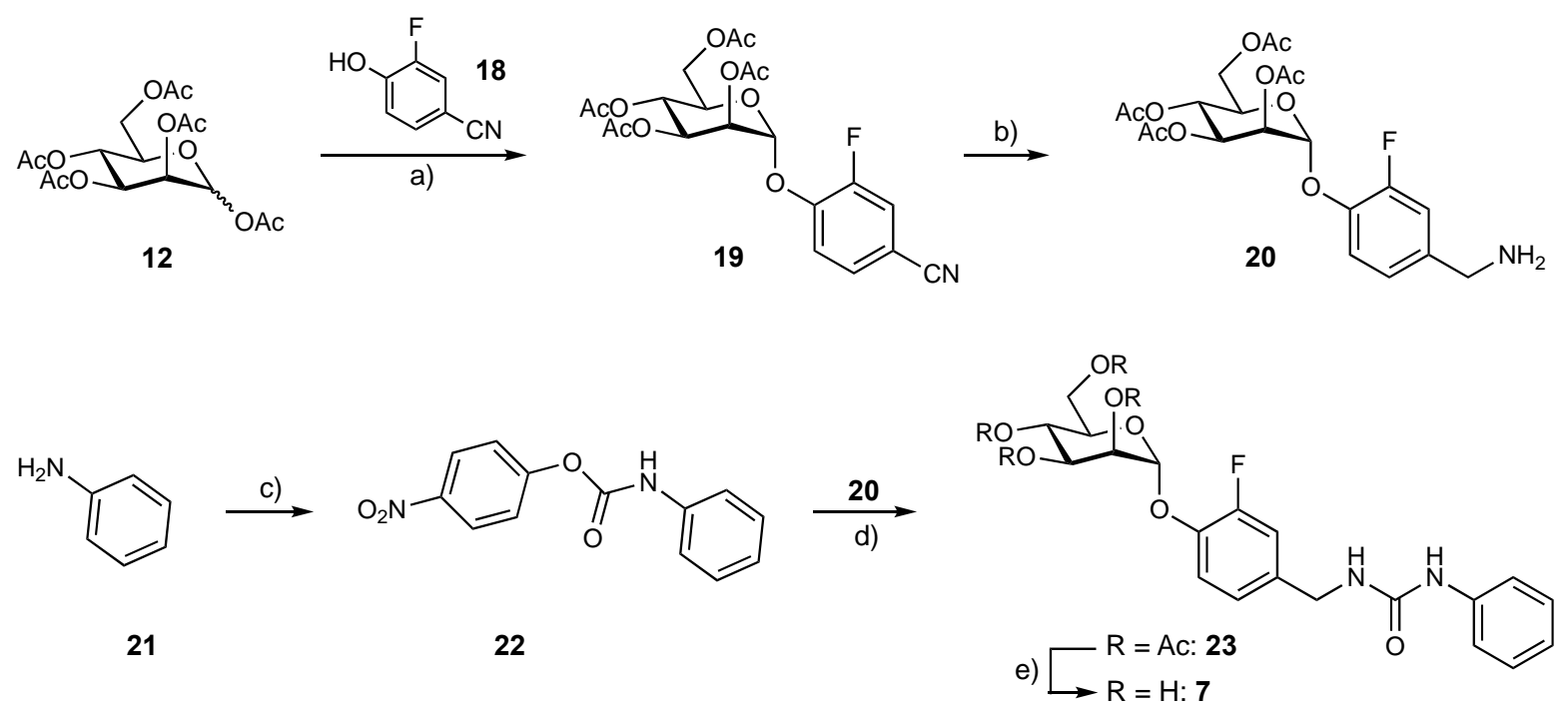

Scheme 4. Reagents and conditions: a) $\mathrm{BF}_{3} \cdot \mathrm{Et}_{2} \mathrm{O}, \mathrm{CH}_{2} \mathrm{Cl}_{2}, \mathrm{MS} 4 \AA \AA^{\circ}, 50{ }^{\circ} \mathrm{C}, 29 \mathrm{~h}, 60 \%$; b) $\mathrm{H}_{2}, \mathrm{Pd}(\mathrm{OH})_{2}, \mathrm{THF} / \mathrm{MeOH}$ (2:1), r.t., 2 h, 64\%; c) 4-nitrophenyl chloroformate, DIPEA, $\mathrm{CH}_{2} \mathrm{Cl}_{2}$, r.t., 22 h, 53\%; d) DIPEA, THF, r.t., 2 h, 19\%; e) $\mathrm{NaOMe} / \mathrm{MeOH}$, r.t., $45 \mathrm{~min}, 83 \%$.

4'-(2,3,4,6-Tetra-O-acetyl- $\alpha$-D-mannopyranosyloxy)-3'-fluorobenzonitrile (19). In a two-necked flask,

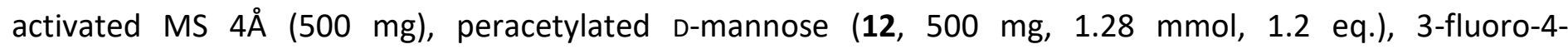
hydroxybenzonitrile (18, $146 \mathrm{mg}, 1.07 \mathrm{mmol}, 1.0$ eq.), and dry $\mathrm{CH}_{2} \mathrm{Cl}_{2}(10 \mathrm{~mL}$ ) were mixed and cooled down in an ice bath. Under argon atmosphere, $\mathrm{BF}_{3} \cdot \mathrm{Et}_{2} \mathrm{O}(395 \mu \mathrm{L}, 3.20 \mathrm{mmol}, 3 \mathrm{eq}$.) was added slowly and the reaction heated to $50{ }^{\circ} \mathrm{C}$. The mixture was refluxed for $29 \mathrm{~h}$. Then, it was diluted with EtOAc, filtered over celite, and subsequently washed with satd. aq. $\mathrm{NaHCO}_{3}$ and brine. The organic layer was dried over $\mathrm{Na}_{2} \mathrm{SO}_{4}$, filtered, and concentrated. The residue was purified by MPLC (toluene/EtOAc, 1:0 to 6:4) to give $19(356 \mathrm{mg}, 60 \%)$. [ $\alpha]_{\mathrm{D}}^{20}$ +88.6 (c 1.00, $\mathrm{CHCl}_{3}$ ); ${ }^{1} \mathrm{H}$ NMR $\left(500 \mathrm{MHz}, \mathrm{CDCl}_{3}\right): \delta 2.03,2.04,2.07,2.21\left(4 \mathrm{~s}, 12 \mathrm{H}, 4 \mathrm{Ac}-\mathrm{CH}_{3}\right), 4.06-4.14(\mathrm{~m}, 2 \mathrm{H}$, $\mathrm{H}-5, \mathrm{H}-6 \mathrm{a}), 4.27$ (dd, J 6.0, $12.9 \mathrm{~Hz}, 1 \mathrm{H}, \mathrm{H}-6 \mathrm{~b}), 5.38$ (t, J $9.9 \mathrm{~Hz}, 1 \mathrm{H}, \mathrm{H}-4$ ), 5.51 (dd, J 1.8, 3.4 Hz, 1H, H-2), 5.53 (dd, J 3.5, 9.9 Hz, 1H, H-3), $5.63(\mathrm{~d}, J 1.4 \mathrm{~Hz}, 1 \mathrm{H}, \mathrm{H}-1), 7.34(\mathrm{t}, J 8.3 \mathrm{~Hz}, 1 \mathrm{H}, \mathrm{Ar}-\mathrm{H}), 7.42-7.48(\mathrm{~m}, 2 \mathrm{H}, \mathrm{Ar}-\mathrm{H}) ;{ }^{13} \mathrm{C}$ NMR (125 MHz, CDCl $): \delta 20.37,20.39,20.41,20.5$ (4 Ac- $\mathrm{CH}_{3}$ ), 61.7 (C-6), 65.4 (C-4), 68.2 (C-3), 68.7 (C-2), 69.9 (C-5), 96.6 (C-1), 107.0 (d, JC,F 8 Hz), 117.1 (d, JC,F 2 Hz), 120.3 (d, JC,F 22 Hz), 129.2 (d, JC,F 4 Hz), 147.2 (d, JC,F 11 $\mathrm{Hz}$ ), 152.2 (d, JC,F $252 \mathrm{~Hz}$; 7C, Ar-C, CN), 169.4, 169.5, 169.6, 170.1 (4 C=O); IR (KBr): v 2232 (w, CN), 1751 (vs, $\mathrm{C}=\mathrm{O}) \mathrm{cm}^{-1}$; ESI-MS: $\mathrm{m} / \mathrm{z}$ : Calcd for $\mathrm{C}_{21} \mathrm{H}_{22} \mathrm{FNNaO}_{10}[\mathrm{M}+\mathrm{Na}]^{+}: 490.11$, found: 490.06 .

4'-(2,3,4,6-Tetra-O-acetyl- $\alpha$-D-mannopyranosyloxy)-3'-fluorophenylmethanamine (20). A two-neckeds flask was charged with 19 (50 mg, $0.107 \mathrm{mmol}$ ) and a magnetic stirrer. Under argon atmosphere, THF/MeOH (6 mL, 2:1) and $\mathrm{Pd}(\mathrm{OH})_{2} / \mathrm{C}(15 \mathrm{mg})$ were added. The flask was evacuated five times and filled with $\mathrm{H}_{2}$. Under hydrogen atmosphere, the mixture was stirred at r.t. until $\mathrm{TLC}\left(\mathrm{CH}_{2} \mathrm{Cl}_{2} / \mathrm{MeOH}, 8: 2\right)$ indicated completion of the reaction. The mixture was filtered over celite, and concentrated. Purification by $\mathrm{MPLC}\left(\mathrm{CH}_{2} \mathrm{Cl}_{2} / \mathrm{MeOH}, 1: 0\right.$ to $\left.8: 2\right)$ gave 20 (32.2 mg, 64\%). $[\alpha]_{\mathrm{D}}^{20}+93.4\left(c 1.00, \mathrm{CHCl}_{3}\right) ;{ }^{1} \mathrm{H} \mathrm{NMR}\left(500 \mathrm{MHz}, \mathrm{CDCl}_{3}\right): \delta 2.03,2.04,2.07,2.20(4 \mathrm{~s}, 12 \mathrm{H}, 4$ Ac- $\left.\mathrm{CH}_{3}\right), 3.83\left(\mathrm{~s}, 2 \mathrm{H}, \mathrm{CH}_{2}\right), 4.10(\mathrm{~d}, J 10.3 \mathrm{~Hz}, 1 \mathrm{H}, \mathrm{H}-6 \mathrm{a}), 4.22-4.30(\mathrm{~m}, 2 \mathrm{H}, \mathrm{H}-5, \mathrm{H}-6 \mathrm{~b}), 5.37(\mathrm{t}, J 10.0 \mathrm{~Hz}, 1 \mathrm{H}, \mathrm{H}-$ 4), 5.46 (d, J $1.6 \mathrm{~Hz}, 1 \mathrm{H}, \mathrm{H}-1), 5.52$ (dd, J 1.8, 3.4 Hz, 1H, H-2), 5.57 (dd, J 3.5, $10.0 \mathrm{~Hz}, 1 \mathrm{H}, \mathrm{H}-3$ ), 7.02 (d, J $8.3 \mathrm{~Hz}$, $1 \mathrm{H}, \mathrm{Ar}-\mathrm{H}), 7.09-7.16(\mathrm{~m}, 2 \mathrm{H}, \mathrm{Ar}-\mathrm{H}) ;{ }^{13} \mathrm{C} \mathrm{NMR}\left(125 \mathrm{MHz}, \mathrm{CDCl}_{3}\right): \delta 20.60,20.63,20.8\left(4 \mathrm{C}, 4 \mathrm{Ac}-\mathrm{CH}_{3}\right), 45.3\left(\mathrm{CH}_{2}\right)$, 62.1 (C-6), 65.8 (C-4), 68.7 (C-3), 69.3 (C-2), 69.5 (C-5), 97.7 (C-1), 115.5 (d, JC,F 19 Hz), 119.4 (d, JC,F 1 Hz), 122.9 
(d, JC,F $3 \mathrm{~Hz}$ ), 139.7 (d, JC,F $6 \mathrm{~Hz}$ ), 141.9 (d, JC,F $11 \mathrm{~Hz}$ ), 153.4 (d, JC,F $248 \mathrm{~Hz} ; 6 \mathrm{C}, \mathrm{Ar}-\mathrm{C}$ ), 160.7, 169.8, 169.8, 170.5 (4 C=O); ESI-MS: $m / z$ : Calcd for $\mathrm{C}_{21} \mathrm{H}_{27} \mathrm{FNO}_{10}[\mathrm{M}+\mathrm{H}]^{+}: 472.16$, found: 472.13 .

4-Nitrophenyl phenylcarbamate (22). To a mixture of aniline (21, $49.0 \mu \mathrm{L}, 0.537 \mathrm{mmol})$ and 4-nitrophenyl chloroformate $(108 \mathrm{mg}, 0.537 \mathrm{mmol})$ in THF $(2 \mathrm{~mL})$ was added DIPEA (91.9 $\mu \mathrm{L}, 0.537 \mathrm{mmol})$. The mixture was stirred at r.t. After $22 \mathrm{~h}$, TLC (toluene/EtOAc, 1:1) indicated no remaining starting materials. The mixture was diluted with EtOAc and washed with $1 \mathrm{M}$ aq. $\mathrm{HCl}$. The aqueous layer was extracted with EtOAc, the combined organic layers were dried over $\mathrm{Na}_{2} \mathrm{SO}_{4}$, filtered and concentrated. The residue was purified by MPLC (toluene/EtOAc, $1: 0$ to $1: 1)$ to give $22(72.8 \mathrm{mg}, 52 \%) .{ }^{1} \mathrm{H} \mathrm{NMR}\left(500 \mathrm{MHz}, \mathrm{CDCl}_{3}\right): \delta 7.06(\mathrm{~s}, 1 \mathrm{H}, \mathrm{NH}), 7.16(\mathrm{t}, J$ $7.4 \mathrm{~Hz}, 1 \mathrm{H}, \mathrm{Ar}-\mathrm{H}), 7.34-7.41(\mathrm{~m}, 4 \mathrm{H}, \mathrm{Ar}-\mathrm{H}), 7.45(\mathrm{~d}, \mathrm{~J} 7.8 \mathrm{~Hz}, 2 \mathrm{H}, \mathrm{Ar}-\mathrm{H}), 8.25-8.31(\mathrm{~m}, 2 \mathrm{H}, \mathrm{Ar}-\mathrm{H}) ;{ }^{13} \mathrm{C} \mathrm{NMR}(125$ $\left.\mathrm{MHz}, \mathrm{CDCl}_{3}\right): \delta 119.0(2 \mathrm{C}), 122.1(2 \mathrm{C}), 124.6,125.2(2 \mathrm{C}), 129.3(2 \mathrm{C}), 136.6,145.1(12 \mathrm{C}, \operatorname{Ar}-\mathrm{C}), 150.1(\mathrm{C}=\mathrm{O})$, $155.4(\mathrm{Ar}-\mathrm{C})$.

1-[4'-(2,3,4,6-Tetra-O-acetyl- $\alpha$-D-mannopyranosyloxy)-3'-fluoro]-3-phenylurea (23). A mixture of 20 (50 mg, $107 \mu \mathrm{mol})$, DIPEA $(18.2 \mu \mathrm{L}, 107 \mu \mathrm{mol})$ and $22(27.4 \mathrm{mg}, 107 \mu \mathrm{mol})$ in dry THF $(2 \mathrm{~mL})$ was stirred at r.t. for $2 \mathrm{~h}$, until TLC $\left(\mathrm{CH}_{2} \mathrm{Cl}_{2} / \mathrm{MeOH}, 9: 1\right)$ showed no remaining starting material. The mixture was diluted with EtOAc and washed with $1 \mathrm{M}$ aq. $\mathrm{HCl}$. The aqueous layer was extracted three times with EtOAc, and the combined organic layers were dried over $\mathrm{Na}_{2} \mathrm{SO}_{4}$, filtered, and concentrated in vacuo. The residue was purified by MPLC $\left(\mathrm{CH}_{2} \mathrm{Cl}_{2} / \mathrm{MeOH}, 1: 0\right.$ to 9:1) to give $23(12.1 \mathrm{mg}, 19 \%)$. $[\alpha]_{\mathrm{D}}^{20}+51.2$ (c $\left.0.61, \mathrm{CHCl}_{3}\right) ;{ }^{1} \mathrm{H} \mathrm{NMR}(500 \mathrm{MHz}, \mathrm{CDCl}): \delta$ = 2.02, 2.03, 2.06, $2.19\left(4 \mathrm{~s}, 12 \mathrm{H}, 4 \mathrm{Ac}-\mathrm{CH}_{3}\right), 4.08$ (dd, J 2.0, $\left.12.1 \mathrm{~Hz}, 1 \mathrm{H}, \mathrm{H}-6 \mathrm{a}\right), 4.20$ (ddd, J 2.0, 5.2, $10.0 \mathrm{~Hz}, 1 \mathrm{H}$, $\mathrm{H}-5), 4.25$ (dd, J 5.2, $12.1 \mathrm{~Hz}, 1 \mathrm{H}, \mathrm{H}-6 \mathrm{~b}), 4.32\left(\mathrm{~d}, J 5.9 \mathrm{~Hz}, 2 \mathrm{H}, \mathrm{CH}_{2}\right), 5.33-5.39(\mathrm{~m}, 2 \mathrm{H}, \mathrm{H}-4, \mathrm{NH}), 5.42(\mathrm{~d}, J 1.5 \mathrm{~Hz}$, $1 \mathrm{H}, \mathrm{H}-1$ ), 5.49 (dd, J 1.8, 3.4 Hz, 1H, H-2), 5.54 (dd, J 3.5, $10.0 \mathrm{~Hz}, 1 \mathrm{H}, \mathrm{H}-3), 6.80(\mathrm{~s}, 1 \mathrm{H}, \mathrm{NH}), 6.96(\mathrm{~d}, J 8.4 \mathrm{~Hz}$, $1 \mathrm{H}, \mathrm{Ar}-\mathrm{H}), 7.03$ (dd, J 1.8, $11.4 \mathrm{~Hz}, 1 \mathrm{H}, \mathrm{Ar}-\mathrm{H}), 7.05-7.11(\mathrm{~m}, 2 \mathrm{H}, \mathrm{Ar}-\mathrm{H}), 7.24-7.30(\mathrm{~m}, 4 \mathrm{H}, \operatorname{Ar}-\mathrm{H}) ;{ }^{13} \mathrm{C} \mathrm{NMR}(125$ $\left.\mathrm{MHz}, \mathrm{CDCl}_{3}\right): \delta$ 20.6, 20.7, $20.8\left(4 \mathrm{C}, 4 \mathrm{Ac}_{-} \mathrm{CH}_{3}\right), 43.2\left(\mathrm{CH}_{2}\right), 62.1(\mathrm{C}-6), 65.8(\mathrm{C}-4), 68.8(\mathrm{C}-3), 69.2(\mathrm{C}-2), 69.6(\mathrm{C}-$ 5), $97.6(C-1), 115.8$ (d, J J,F $19 \mathrm{~Hz}), 119.4,121.1,123.3\left(\mathrm{~d}, J_{C, F} 4 \mathrm{~Hz}\right), 124.1,129.3,135.9\left(\mathrm{~d}, J_{C, F} 6 \mathrm{~Hz}\right), 138.2$, 142.3 (d, JC,F $11 \mathrm{~Hz}$ ), 153.4 (d, JC,F $249 \mathrm{~Hz} ; 12 \mathrm{C}, \mathrm{Ar}-\mathrm{C}), 155.8$ (C=O(NH)2), 169.7, 169.9, 170.0, 170.6 (4 C=O); ESIMS: $m / z$ : Calcd for $\mathrm{C}_{28} \mathrm{H}_{31} \mathrm{FN}_{2} \mathrm{NaO}_{11}[\mathrm{M}+\mathrm{Na}]^{+}$: 613.18, found: 613.31 .

1-(3'-Fluoro-4'- $\alpha$-D-mannopyranosyloxy)-3-phenylurea (7). Prepared according to general procedure $\mathrm{B}$ from 23 (12.1 mg, $20.5 \mu \mathrm{mol})$. Yield: $7.2 \mathrm{mg}(83 \%)$. $[\alpha]_{\mathrm{D}}^{20}+88.1$ (c 0.36, MeOH); ${ }^{1} \mathrm{H} \mathrm{NMR}\left(500 \mathrm{MHz}, \mathrm{CD}_{3} \mathrm{OD}\right): \delta 3.66-$ 3.80 (m, 4H, H-4, H-5, H6a, H-6b), 3.91 (dd, J 3.4, 9.2 Hz, 1H, H-3), 4.06 (dd, J 1.8, 3.3 Hz, 1H, H-2), 5.44 (d, J 1.6 $\mathrm{Hz}, 1 \mathrm{H}, \mathrm{H}-1), 6.97(\mathrm{t}, J 7.4 \mathrm{~Hz}, 1 \mathrm{H}, \mathrm{Ar}-\mathrm{H}), 7.07$ (d, J $8.4 \mathrm{~Hz}, 1 \mathrm{H}, \mathrm{Ar}-\mathrm{H}), 7.11$ (dd, J 1.9, $11.9 \mathrm{~Hz}, 1 \mathrm{H}, \mathrm{Ar}-\mathrm{H}), 7.21-$ $7.28(\mathrm{~m}, 2 \mathrm{H}, \mathrm{Ar}-\mathrm{H}), 7.31(\mathrm{t}, J 8.4 \mathrm{~Hz}, 1 \mathrm{H}, \mathrm{Ar}-\mathrm{H}), 7.35$ (dd, J 1.0, $8.5 \mathrm{~Hz}, 2 \mathrm{H}, \mathrm{Ar}-\mathrm{H}) ;{ }^{13} \mathrm{C} \mathrm{NMR}\left(125 \mathrm{MHz}, \mathrm{CD}{ }_{3} \mathrm{OD}\right): \delta$ $43.6\left(\mathrm{CH}_{2}\right), 62.6$ (C-6), 68.2 (C-4), 71.9 (C-2), 72.3 (C-3), 75.8 (C-5), 101.7 (C-1), 116.2 (d, JC,F 19 Hz), 120.3, 123.6, 124.3 (d, J J,F $3 \mathrm{~Hz}$ ), 129.8, 137.0 (d, JC,F $6 \mathrm{~Hz}$ ), 140.8, 144.4 (d, JC,F $11 \mathrm{~Hz}), 154.6$ (d, JC,F $246 \mathrm{~Hz} ; 12 \mathrm{C}, \mathrm{Ar}-$ C), 158.2 (C=O); IR (KBr): v 3371 (vs, OH), 1651 (s, C=O) cm ; $\mathrm{HRMS}^{-1} \mathrm{~m} / z$ : Calcd for $\mathrm{C}_{20} \mathrm{H}_{24} \mathrm{FN}_{2} \mathrm{NaO}_{7}\left[\mathrm{M}+\mathrm{Na}^{+}\right.$: 445.1387, found: 445.1385 .
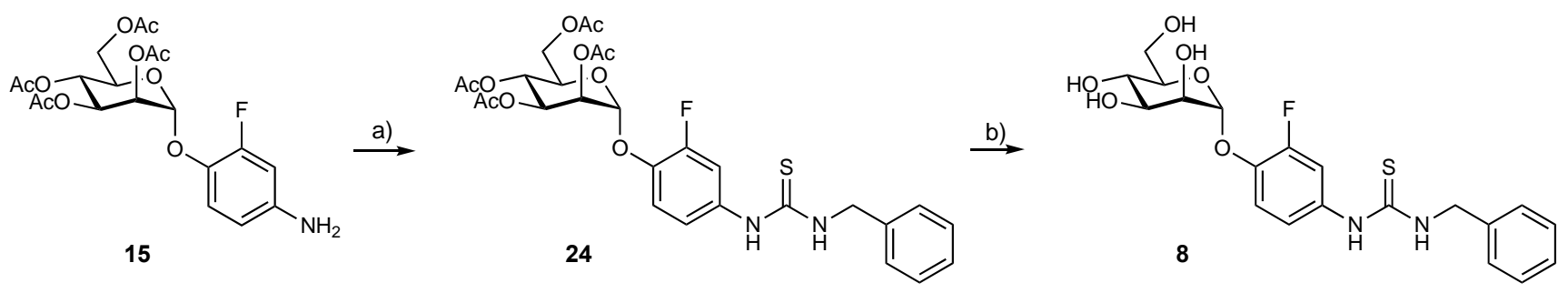

Scheme 5. Reagents and conditions: a) i. TCDI, $\mathrm{CH}_{2} \mathrm{Cl}_{2}$, r.t., $17 \mathrm{~h}$; ii. benzylamine, $\mathrm{CH}_{2} \mathrm{Cl}_{2}$, r.t., 3 h, $52 \%$ (over two steps); b) NaOMe, $\mathrm{MeOH}, 0^{\circ} \mathrm{C}, 45 \mathrm{~min}, 71 \%$. 
1-Benzyl-3-[4'-(2,3,4,6-tetra-O-acetyl- $\alpha$-D-mannopyranosyloxy)-3'-fluorophenyl]thiourea (24). Compound 15 (47.0 mg, $0.103 \mathrm{mmol}$ ) and 1,1'-thiocarbonyldiimidazole (TCDI; $18.3 \mathrm{mg}, 0.103 \mathrm{mmol}$.) were dissolved in dry $\mathrm{CH}_{2} \mathrm{Cl}_{2}(2 \mathrm{~mL})$. The mixture was stirred at r.t. for $17 \mathrm{~h}$. Then benzylamine $(11.2 \mu \mathrm{L}, 0.103 \mathrm{mmol})$ was added and the mixture was stirred for $3 \mathrm{~h}$ until TLC (petroleum ether/EtOAc, 1:1) showed no remaining starting material. The mixture was diluted with $\mathrm{CH}_{2} \mathrm{Cl}_{2}$, and washed with $1 \mathrm{M}$ aq. $\mathrm{HCl}$, satd. aq. $\mathrm{NaHCO}_{3}$ and brine. The organic layer was dried over $\mathrm{Na}_{2} \mathrm{SO}_{4}$, filtered, and concentrated in vacuo. The residue was purified by MPLC (petroleum ether/EtOAc, 1:0 to 0:1) to give $24(32.3 \mathrm{mg}, 52 \%)$. [ $\alpha]_{\mathrm{D}}^{20}+51.6$ (c 1.07, $\left.\mathrm{CHCl}_{3}\right) ;{ }^{1} \mathrm{H} \mathrm{NMR}(500 \mathrm{MHz}$, $\left.\mathrm{CDCl}_{3}\right): \delta$ 1.96, 1.99, 2.02, 2.15 (4 s, 12H, $\left.4 \mathrm{Ac}-\mathrm{CH}_{3}\right), 4.04$ (dd, J 2.4, $\left.12.1 \mathrm{~Hz}, 1 \mathrm{H}, \mathrm{H}-6 \mathrm{a}\right), 4.12$ (ddd, J 2.3, 5.2, $10.1 \mathrm{~Hz}, 1 \mathrm{H}, \mathrm{H}-5), 4.20$ (dd, J 5.2, $12.2 \mathrm{~Hz}, 1 \mathrm{H}, \mathrm{H}-6 \mathrm{~b}), 4.81$ (d, J $5.2 \mathrm{~Hz}, 2 \mathrm{H}, \mathrm{CH}_{2}$ ), 5.32 (t, J $\left.10.1 \mathrm{~Hz}, 1 \mathrm{H}, \mathrm{H}-4\right), 5.41$ (s, $1 \mathrm{H}, \mathrm{H}-1), 5.43$ (dd, J 1.8, 3.3 Hz, 1H, H-2), 5.48 (dd, J 3.4, $10.0 \mathrm{~Hz}, 1 \mathrm{H}, \mathrm{H}-3), 6.23(\mathrm{~s}, 1 \mathrm{H}, \mathrm{NH}), 6.92(\mathrm{~d}, J 8.7 \mathrm{~Hz}$, $1 \mathrm{H}, \mathrm{Ar}-\mathrm{H}$ ), 7.02 (dd, J 2.2, $11.0 \mathrm{~Hz}, 1 \mathrm{H}, \mathrm{Ar}-\mathrm{H}), 7.16(\mathrm{t}, J 8.7 \mathrm{~Hz}, 1 \mathrm{H}, \mathrm{Ar}-\mathrm{H}), 7.22-7.27(\mathrm{~m}, 3 \mathrm{H}, \mathrm{Ar}-\mathrm{H}), 7.27-7.32(\mathrm{~m}$, $2 \mathrm{H}, \mathrm{Ar}-\mathrm{H}), 7.96(\mathrm{~s}, 1 \mathrm{H}, \mathrm{NH}) ;{ }^{13} \mathrm{C} N M R\left(125 \mathrm{MHz}, \mathrm{CDCl}_{3}\right): \delta 20.59,20.61,20.62,20.8\left(4 \mathrm{Ac}-\mathrm{CH}_{3}\right), 49.4\left(\mathrm{CH}_{2}\right), 62.1$ (C-6), 65.7 (C-4), 68.5 (C-3), 69.1 (C-2), 69.7 (C-5), 97.5 (C-1), 114.4 (d, JC,F $20 \mathrm{~Hz}$ ), 119.9 (d, JC,F 2 Hz), 121.6 (d, $\left.J_{C, F} 4 \mathrm{~Hz}\right), 127.7,127.9,128.8,137.0,142.4$ (d, JC,F $11 \mathrm{~Hz}$ ), 153.4 (d, JC,F $\left.252 \mathrm{~Hz} ; 12 \mathrm{C}, \mathrm{Ar}-\mathrm{C}\right), 169.7,169.8,169.9$, 170.4 (4 C=O), 181.1 (C=S); ESI-MS: $m / z$ : Calcd for $\mathrm{C}_{28} \mathrm{H}_{32} \mathrm{FN}_{2} \mathrm{O}_{10} \mathrm{~S}[\mathrm{M}+\mathrm{H}]^{+}:$: 607.18, found: 607.30 .

1-Benzyl-3-[3-fluoro-4-( $\alpha$-D-mannopyranosyloxy)phenyl]thiourea (8). Prepared according to general procedure B from 24 (32.2 mg, $53.1 \mu \mathrm{mol})$. Yield: $16.7 \mathrm{mg}(71 \%)$. [ $\alpha]_{\mathrm{D}}^{20}+95.6$ (c 0.84, MeOH); ${ }^{1} \mathrm{H} \mathrm{NMR}(500$ $\mathrm{MHz}, \mathrm{CD}_{3} \mathrm{OD}$ ): $\delta$ 3.65-3.81 (m, 4H, H-4, H-5, H-6a, H-6b), 3.90 (dd, J 3.4, $9.1 \mathrm{~Hz}, 1 \mathrm{H}, \mathrm{H}-3$ ), 4.06 (dd, J 1.8, 3.3 $\mathrm{Hz}, 1 \mathrm{H}, \mathrm{H}-2), 4.80$ (s, 2H, CH ), 5.45 (d, J $1.6 \mathrm{~Hz}, 1 \mathrm{H}, \mathrm{H}-1), 7.03$ (ddd, J 1.4, 2.3, 8.8 Hz, 1H, Ar-H), $7.25(\mathrm{~m}, 1 \mathrm{H}$, Ar-H), 7.27-7.36 (m, 6H, Ar-H); ${ }^{13} \mathrm{C} \mathrm{NMR} \mathrm{(125} \mathrm{MHz,} \mathrm{CD} \mathrm{ND}_{3}$ ): $\delta 49.0\left(\mathrm{CH}_{2}\right), 62.7$ (C-6), 68.2 (C-4), 71.8 (C-2), 72.3 (C-3), 75.9 (C-5), 101.7 (C-1), 114.5 (d, JC,F 21 Hz), 120.4, 121.9 (d, JC,F 5 Hz), 128.2, 128.6, 129.5, 135.1 (d, JC,F 9 $\mathrm{Hz}$ ), 139.9, 143.2 (d, JC,F $11.0 \mathrm{~Hz}$ ), 154.3 (d, JC,F $246 \mathrm{~Hz} ; 12 \mathrm{C}, \mathrm{Ar}-\mathrm{C}), 182.9$ (C=S); IR (KBr): v 3295 (vs, OH), 1563 (vs), 1509 (vs) cm ${ }^{-1}$; HRMS: $\mathrm{m} / \mathrm{z}$ : Calcd for $\mathrm{C}_{20} \mathrm{H}_{24} \mathrm{FN}_{2} \mathrm{NaO}_{6} \mathrm{~S}[\mathrm{M}+\mathrm{Na}]^{+}: 461.1159$ found: 461.1161.
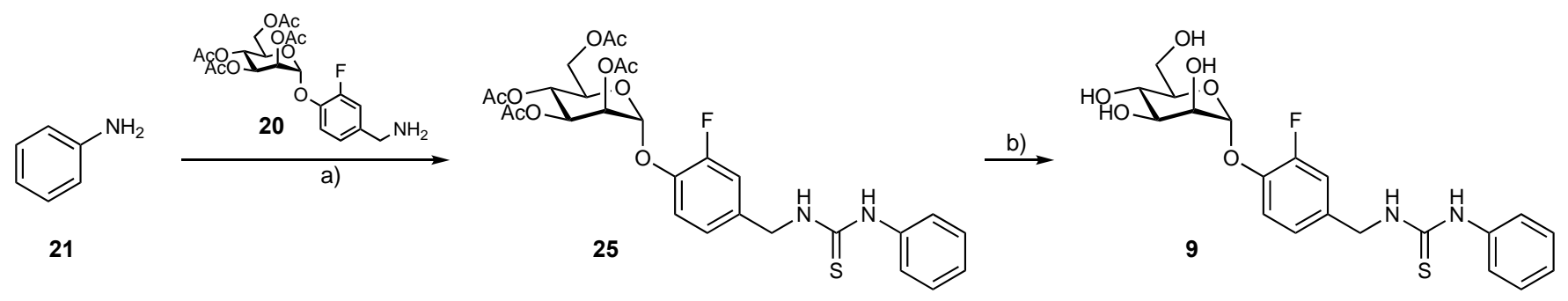

Scheme 6. Reagents and conditions: a) i. $\mathrm{TCDI}, \mathrm{CH}_{2} \mathrm{Cl}_{2}$, r.t., $18 \mathrm{~h}$; ii. 20, $\mathrm{CH}_{2} \mathrm{Cl}_{2}$, r.t., 6 h, 7\% (over two steps); b) $\mathrm{NaOMe}, \mathrm{MeOH}$, r.t., $45 \mathrm{~min}, 66 \%$.

1-[4'-(2,3,4,6-Tetra-O-acetyl- $\alpha$-D-mannopyranosyloxy)-3'-fluorobenzyl]-3-phenylthiourea $\quad(25) . \quad 1,1^{\prime}$-Thiocarbonyldiimidazole $\left(18.9 \mathrm{mg}, 0.106 \mathrm{mmol}\right.$ ) was dissolved in dry $\mathrm{CH}_{2} \mathrm{Cl}_{2}(2 \mathrm{~mL})$ and 21 (9.7 $\left.\mu \mathrm{L}, 0.106 \mathrm{mmol}\right)$ was added. The mixture was stirred at r.t. for $18 \mathrm{~h}$ until TLC (toluene/EtOAc, 1:1) showed no remaining aniline. Then, 20 (50 mg, $0.106 \mathrm{mmol})$ in dry $\mathrm{CH}_{2} \mathrm{Cl}_{2}(2 \mathrm{~mL})$ was added and the mixture stirred for another $6 \mathrm{~h}$. Then, it was diluted with $\mathrm{CH}_{2} \mathrm{Cl}_{2}$ and subsequently washed with $1 \mathrm{M}$ aq. $\mathrm{HCl}$, satd. aq. $\mathrm{NaHCO}_{3}$, and brine. The organic layer was dried over $\mathrm{Na}_{2} \mathrm{SO}_{4}$, filtered, and the solvent removed. The residue was purified by MPLC (toluene/EtOAc, $1: 0$ to $1: 1$ ) to give 25 (4.8 mg, $7 \%$ ). $[\alpha]_{\mathrm{D}}^{20}+49.8\left(c 0.24, \mathrm{CHCl}_{3}\right) ;{ }^{1} \mathrm{H} \mathrm{NMR}(500 \mathrm{MHz}, \mathrm{CDCl} 3): \delta$ 2.03, 2.06, 2.19 (3 s, 12H, 4 Ac- $\mathrm{CH}_{3}$ ), 4.09 (dd, J 1.9, $\left.12.2 \mathrm{~Hz}, 1 \mathrm{H}, \mathrm{H}-6 \mathrm{a}\right), 4.20$ (ddd, J 1.8, 5.2, 9.9 Hz, 1H, H-5), 4.26 (dd, J 5.3, $12.1 \mathrm{~Hz}, 1 \mathrm{H}, \mathrm{H}-6 \mathrm{~b}), 4.83\left(\mathrm{~d}, J 5.7 \mathrm{~Hz}, 2 \mathrm{H}, \mathrm{CH}_{2}\right), 5.36(\mathrm{t}, J 10.0 \mathrm{~Hz}, 1 \mathrm{H}, \mathrm{H}-4), 5.45(\mathrm{~s}, 1 \mathrm{H}, \mathrm{H}-1), 5.49$ (m, 1H, H-2), 5.55 (dd, J 3.5, $10.0 \mathrm{~Hz}, 1 \mathrm{H}, \mathrm{H}-3), 6.22(\mathrm{~s}, 1 \mathrm{H}, \mathrm{NH}), 7.01(\mathrm{~d}, J 8.4 \mathrm{~Hz}, 1 \mathrm{H}, \mathrm{Ar}-\mathrm{H}), 7.09$ (dd, J 1.5, 11.3 
$\mathrm{Hz}, 1 \mathrm{H}, \mathrm{Ar}-\mathrm{H}), 7.12(\mathrm{t}, \mathrm{J} 8.2 \mathrm{~Hz}, 1 \mathrm{H}, \mathrm{Ar}-\mathrm{H}), 7.15-7.26(\mathrm{~m}, 2 \mathrm{H}, \mathrm{Ar}-\mathrm{H}), 7.34(\mathrm{~m}, 1 \mathrm{H}, \mathrm{Ar}-\mathrm{H}), 7.44(\mathrm{t}, J 7.8 \mathrm{~Hz}, 2 \mathrm{H}, \mathrm{Ar}-$

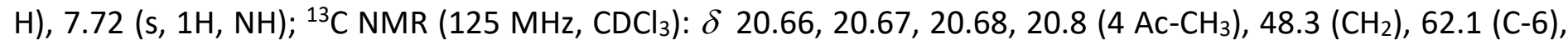
65.8 (C-4), 68.7 (C-3), 69.3 (C-2), 69.6 (C-5), 97.6 (C-1), 116.1 (d, JC,F 19 Hz), 119.3, 123.6 (d, J J,F 4 Hz), 125.6, 127.8, 128.8, 130.4, 134.0 (d, J $6 \mathrm{~Hz}), 142.8$ (d, JC,F $11 \mathrm{~Hz}$ ), 153.4 (d, JC,F $249 \mathrm{~Hz} ; 12 \mathrm{C}, \operatorname{Ar}-\mathrm{C}), 169.7,169.8,169.9$, 170.5 (4 C=O), 181.3 (C=S); ESI-MS: $m / z$ : Calcd for $\mathrm{C}_{28} \mathrm{H}_{31} \mathrm{FN}_{2} \mathrm{NaO}_{10} \mathrm{~S}[\mathrm{M}+\mathrm{H}]^{+}:$: 629.16, found: 629.15 .

1-(3-Fluoro-4- $\alpha$-D-mannopyranosyloxybenzyl)-3-phenylthiourea (9). Prepared according to general procedure B from 25 (4.6 mg, $7.9 \mu \mathrm{mol})$. Yield: $2.3 \mathrm{mg}(66 \%)$. [ $\alpha]_{\mathrm{D}}^{20}+61.4(c 0.12, \mathrm{MeOH}) ;{ }^{1} \mathrm{H} \mathrm{NMR}\left(500 \mathrm{MHz}, \mathrm{CD}_{3} \mathrm{OD}\right): \delta=$ 3.66-3.79 (m, 4H, H-4, H-5, H-6a, H-6b), 3.91 (dd, J 3.4, 9.1 Hz, 1H, H-3), 4.06 (dd, J 1.8, 3.4 Hz, 1H, H-2), 4.76 (s, 2H, CH ), 5.45 (d, J $1.7 \mathrm{~Hz}, 1 \mathrm{H}, \mathrm{H}-1), 7.09$ (d, J $8.4 \mathrm{~Hz}, 1 \mathrm{H}, \mathrm{Ar}-\mathrm{H}), 7.15$ (dd, J 2.0, 11.9 Hz, 1H, Ar-H), $7.21(\mathrm{~m}$, $1 \mathrm{H}, \mathrm{Ar}-\mathrm{H}), 7.28-7.39(\mathrm{~m}, 5 \mathrm{H}, \mathrm{Ar}-\mathrm{H}) ;{ }^{13} \mathrm{C} \mathrm{NMR}\left(125 \mathrm{MHz}, \mathrm{CD}_{3} \mathrm{OD}\right): \delta 48.2\left(\mathrm{CH}_{2}\right), 62.6$ (C-6), 68.2 (C-4), 71.9 (C-2), 72.3 (C-3), 75.8 (C-5), 101.7 (C-1), 116.6 (d, JC,F $19 \mathrm{~Hz}$ ), 120.2 (d, J J,F $1 \mathrm{~Hz}$ ), 124.7 (d, JC,F $3 \mathrm{~Hz}$ ), 125.9 (d, JC,F 3 $\mathrm{Hz}), 127.0,130.3,139.5,144.4,154.5\left(\mathrm{~d}, \mathrm{~J}_{\mathrm{C}, \mathrm{F}} 246 \mathrm{~Hz} ; 12 \mathrm{C}, \mathrm{Ar}-\mathrm{C}\right), 182.8(\mathrm{C}=\mathrm{S}) ; \mathrm{IR}(\mathrm{KBr}): v 3422(\mathrm{vs}, \mathrm{OH}), 1514$ $(\mathrm{m}, \mathrm{NH}) \mathrm{cm}^{-1}$; HRMS: $\mathrm{m} / \mathrm{z}$ : Calcd for $\mathrm{C}_{20} \mathrm{H}_{24} \mathrm{FN}_{2} \mathrm{NaO}_{6} \mathrm{~S}[\mathrm{M}+\mathrm{Na}]^{+}: 461.1159$ found: 461.1160 .

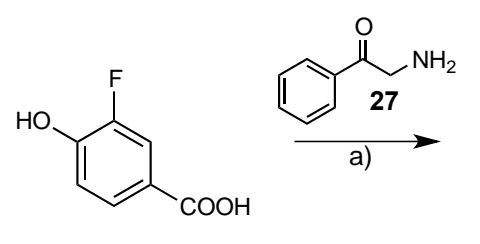

26

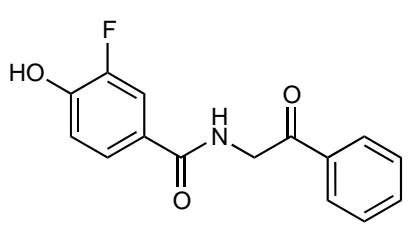

28

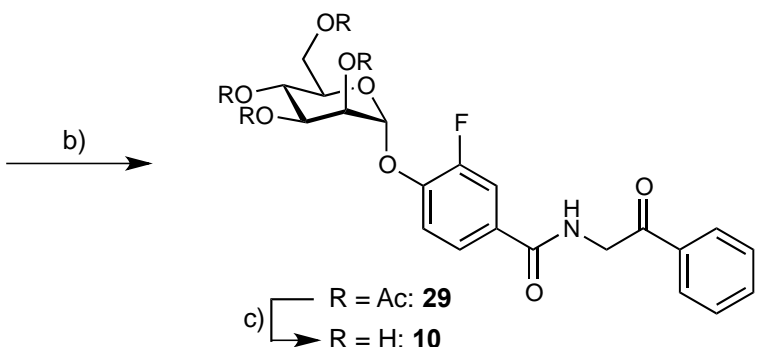

Scheme 7. Reagents and conditions: a) HBTU, $\mathrm{HOBt}$, DIPEA, DMF, r.t., 2.5 h, $18 \%$; b) $11, \mathrm{BF}_{3} \cdot \mathrm{Et}_{2} \mathrm{O}, \mathrm{CH}_{2} \mathrm{Cl}_{2} /$ $\mathrm{MeCN}, \mathrm{MS} 4 \AA \AA$, $50-75^{\circ} \mathrm{C}, 48 \mathrm{~h}, 12 \%$; c) NaOMe, $\mathrm{MeOH}$, r.t., $45 \mathrm{~min}, 60 \%$.

3-Fluoro-4-hydroxy-N-(2-oxo-2-phenylethyl)benzamide (28). 3-Fluoro-4-hydroxybenzoic acid (26, $50.0 \mathrm{mg}$, $0.641 \mathrm{mmol}, 1$ eq.), HBTU (243 mg, $1.28 \mathrm{mmol}, 2$ eq.), HOBt hydrate (12\% water; $98.4 \mathrm{mg}, 0.205 \mathrm{mmol}, 2$ eq.), and 2-aminoacetophenone hydrochloride $(27,35.2 \mathrm{mg}, 1.28 \mathrm{mmol}, 2$ eq.) were dissolved in anhydrous DMF (1.5 mL). Then, DIPEA (110 $\mu \mathrm{L}, 2.56 \mathrm{mmol}, 4$ eq.) was added and the mixture was stirred at r.t. for $2.5 \mathrm{~h}$. Then, it was diluted with EtOAc and subsequently washed with $1 \mathrm{M}$ aq. $\mathrm{HCl}$ and brine. The organic layer was dried over $\mathrm{Na}_{2} \mathrm{SO}_{4}$, filtered and the solvents were removed in vacuo. The residue was purified by MPLC (toluene/EtOAc, 1:0 to 1:1) to give 28 (31.8 mg, 18\%). ${ }^{1} \mathrm{H} \mathrm{NMR}\left(500 \mathrm{MHz}, \mathrm{CD}_{3} \mathrm{OD}\right): \delta 4.86\left(\mathrm{~s}, 2 \mathrm{H}, \mathrm{CH}_{2}\right), 6.99(\mathrm{t}, \mathrm{J}$ $8.5 \mathrm{~Hz}, 1 \mathrm{H}, \mathrm{Ar}-\mathrm{H}), 7.53(\mathrm{t}, \mathrm{J} 7.7 \mathrm{~Hz}, 2 \mathrm{H}, \mathrm{Ar}-\mathrm{H}), 7.60$ (dd, J 2.1, 8.4 Hz, 1H, Ar-H), 7.62-7.67 (m, 2H, Ar-H), 8.02$8.08(\mathrm{~m}, 2 \mathrm{H}, \mathrm{Ar}-\mathrm{H}) ;{ }^{13} \mathrm{C} \mathrm{NMR}\left(125 \mathrm{MHz}, \mathrm{CD}_{3} \mathrm{OD}\right): \delta 47.7\left(\mathrm{CH}_{2}\right), 116.5\left(\mathrm{~d}, J_{\mathrm{C}, \mathrm{F}} 20 \mathrm{~Hz}\right), 118.5\left(\mathrm{~d}, J_{\mathrm{C}, \mathrm{F}} 3 \mathrm{~Hz}\right), 125.3(\mathrm{~d}$, $\left.J_{C, F} 3 \mathrm{~Hz}\right), 126.7\left(\mathrm{~d}, J_{C, F} 6 \mathrm{~Hz}\right), 129.0,129.9,134.8,136.5,150.0\left(\mathrm{~d}, J_{C, F} 13 \mathrm{~Hz}\right), 152.4\left(\mathrm{~d}, J_{C, F} 242 \mathrm{~Hz} ; 12 \mathrm{C}, \mathrm{Ar}-\mathrm{C}\right)$, 169.1 (CONH), 196.4 (C=O); ESI-MS: $m / z$ : Calcd for $\mathrm{C}_{15} \mathrm{H}_{12} \mathrm{FNNaO}_{3}[\mathrm{M}+\mathrm{Na}]^{+}:$296.07, found: 295.49 .

4-(2,3,4,6-Tetra-O-acetyl- $\alpha$-D-mannopyranosyloxy)-3-fluoro- $N$-(2-oxo-2-phenylethyl)benzamide (29). A twonecked flask was charged with activated MS $4 \AA$ (50 mg), peracetylated D-mannose $(12,54.5 \mathrm{mg}, 0.140 \mathrm{mmol}$, 1.2 eq.) and dry $\mathrm{CH}_{2} \mathrm{Cl}_{2}(2 \mathrm{~mL})$. Under argon atmosphere, 28 (31.8 mg, $0.116 \mathrm{mmol}, 1$ eq.) in dry $\mathrm{MeCN}(2 \mathrm{~mL})$ was added. The mixture was refluxed at $50{ }^{\circ} \mathrm{C}$ for $24 \mathrm{~h}$, and another $24 \mathrm{~h}$ at $75^{\circ} \mathrm{C}$. When TLC (petroleum ether/EtOAc, 1:1) showed no remaining mannose precursor, the mixture was diluted with EtOAc, filtered over celite, and washed with satd. aq. $\mathrm{NaHCO}_{3}$ and brine. The organic layer was dried over $\mathrm{Na}_{2} \mathrm{SO}_{4}$, filtered and concentrated. The residue was purified by MPLC (petroleum ether/EtOAc, 1:0 to 1:1) to yield 29 (8.3 mg, 12\%). Unreacted $28(15.5 \mathrm{mg}, 49 \%)$ could be recovered. $[\alpha]_{\mathrm{D}}^{20}+60.1\left(c 0.42, \mathrm{CHCl}_{3}\right) ;{ }^{1} \mathrm{H} \mathrm{NMR}\left(500 \mathrm{MHz} \mathrm{CDCl}_{3}\right): \delta$ 
2.04, 2.04, 2.07, 2.21 (4 s, 12H, 4 Ac- $\mathrm{CH}_{3}$ ), 4.09 (dd, J 2.1, $\left.12.2 \mathrm{~Hz}, 1 \mathrm{H}, \mathrm{H}-6 \mathrm{a}\right), 4.16$ (ddd, J 1.9, 5.3, 9.9 Hz, 1H, H5), 4.28 (dd, J 5.4, $12.3 \mathrm{~Hz}, 1 \mathrm{H}, \mathrm{H}-6 \mathrm{~b}), 4.94$ (d, J $4.1 \mathrm{~Hz}, 2 \mathrm{H}, \mathrm{CH}_{2}$ ), 5.38 (t, J $10.1 \mathrm{~Hz}, 1 \mathrm{H}, \mathrm{H}-4$ ), 5.53 (dd, J $1.8,3.3$ $\mathrm{Hz}, 1 \mathrm{H}, \mathrm{H}-2), 5.55-5.60(\mathrm{~m}, 2 \mathrm{H}, \mathrm{H}-3, \mathrm{H}-1), 7.22(\mathrm{~s}, 1 \mathrm{H}, \mathrm{NH}), 7.28(\mathrm{t}, J 8.2 \mathrm{~Hz}, 1 \mathrm{H}, \mathrm{Ar}-\mathrm{H}), 7.53(\mathrm{t}, J 7.7 \mathrm{~Hz}, 2 \mathrm{H}, \mathrm{Ar}-$ H), 7.62 (d, J $8.6 \mathrm{~Hz}, 1 \mathrm{H}, \mathrm{Ar}-\mathrm{H}), 7.65$ (t, J $7.4 \mathrm{~Hz}, 1 \mathrm{H}, \mathrm{Ar}-\mathrm{H}), 7.70$ (dd, J 1.9, $11.1 \mathrm{~Hz}, 1 \mathrm{H}, \mathrm{Ar}-\mathrm{H}), 8.03$ (d, J $7.5 \mathrm{~Hz}$, $2 \mathrm{H}, \mathrm{Ar}-\mathrm{H}) ;{ }^{13} \mathrm{C}$ NMR $\left(125 \mathrm{MHz}, \mathrm{CDCl}_{3}\right): \delta 20.64,20.65,20.66,20.8\left(4 \mathrm{Ac}_{-} \mathrm{CH}_{3}\right), 46.9\left(\mathrm{CH}_{2}\right), 62.0(\mathrm{C}-6), 65.7(\mathrm{C}-4)$, 68.6 (C-3), 69.1 (C-2), 69.8 (C-5), 97.0 (C-1), 116.2 (d, JC,F 20 Hz), 118.1, 123.4 (d, JC,F $4 \mathrm{~Hz}$ ), 128.0, 129.0, 129.9 (d, $\left.J_{C, F} 6 \mathrm{~Hz}\right), 134.2,134.4,146.1$ (d, JC,F $11 \mathrm{~Hz}$ ), 152.8 (d, JC,F $\left.250 \mathrm{~Hz} ; 12 \mathrm{C}, \operatorname{Ar}-\mathrm{C}\right), 165.4,169.7,169.8,169.9$, 170.5, 194.0 (6 C=O); ESI-MS: $m / z$ : Calcd for $\mathrm{C}_{29} \mathrm{H}_{30} \mathrm{FNNaO}_{12}[\mathrm{M}+\mathrm{Na}]^{+}: 626.17$, found: 626.24 .

3-Fluoro-4- $\alpha$-D-mannopyranosyloxy- $\mathbf{N}$-(2-oxo-2-phenylethyl)benzamide (10). Prepared according to general procedure B from 29. Yield: $3.6 \mathrm{mg}(60 \%)$. $[\alpha]_{\mathrm{D}}^{20}+88.3$ (c $\left.0.18, \mathrm{MeOH}\right) ;{ }^{1} \mathrm{H} \mathrm{NMR}\left(500 \mathrm{MHz}, \mathrm{CD}_{3} \mathrm{OD}\right): \delta 3.62$ (ddd, J 2.4, 5.6, 9.8 Hz, 1H, H-5), 3.68-3.81 (m, 3H, H-4, H-6a, H-6b), 3.93 (dd, J 3.4, 9.5 Hz, 1H, H-3), 4.09 (dd, J 1.8, $3.4 \mathrm{~Hz}, 1 \mathrm{H}, \mathrm{H}-2), 4.87\left(\mathrm{~s}, 2 \mathrm{H}, \mathrm{CH}_{2}\right), 5.62(\mathrm{~d}, J 1.5 \mathrm{~Hz}, 1 \mathrm{H}, \mathrm{H}-1), 7.50(\mathrm{t}, J 8.5 \mathrm{~Hz}, 1 \mathrm{H}, \mathrm{Ar}-\mathrm{H}), 7.55(\mathrm{t}, J 7.7 \mathrm{~Hz}, 2 \mathrm{H}, \mathrm{Ar}-$ $\mathrm{H}), 7.66(\mathrm{t}, J 7.4 \mathrm{~Hz}, 1 \mathrm{H}, \mathrm{Ar}-\mathrm{H}), 7.68-7.74(\mathrm{~m}, 2 \mathrm{H}, \mathrm{Ar}-\mathrm{H}), 8.04-8.08(\mathrm{~m}, 2 \mathrm{H}, \mathrm{Ar}-\mathrm{H}) ;{ }^{13} \mathrm{C} \mathrm{NMR}\left(125 \mathrm{MHz}, \mathrm{CD}{ }_{3} \mathrm{OD}\right): \delta$ 62.6 (C-6), 68.2 (C-4), 71.7 (C-2), 72.3 (C-3), 76.1 (C-5), 101.0 (C-1), 116.6 (d, J J,F $20 \mathrm{~Hz}$ ), 119.0, 125.2 (d, J J,F 4 $\mathrm{Hz}$ ), 129.1, 130.0, 134.9, 136.5, 148.5 (d, J J,F $11 \mathrm{~Hz}), 153.9$ (d, J J,F $246 \mathrm{~Hz} ; 12 \mathrm{C}, \operatorname{Ar}-\mathrm{C}), 168.7$ (CONH), 196.3 $(\mathrm{C}=\mathrm{O})$; IR (KBr): $v 3412$ (vs, $\mathrm{OH}, \mathrm{NH}), 1646$ (s, C=O) $\mathrm{cm}^{-1}$; HRMS: $\mathrm{m} / \mathrm{z}$ : Calcd for $\mathrm{C}_{21} \mathrm{H}_{23} \mathrm{FNNaO}_{8}[\mathrm{M}+\mathrm{Na}]^{+}$: 458.1227, found: 458.1227 .

\section{Supplementary Material}

For Surface Plasmon Resonance Experiments and Fluorescence Polarization Assay please refer to the Supporting Information for a detailed description.

\section{References}

1. Herrmann, A. Chem. Soc. Rev. 2014, 43, 1899-1933.

https://doi.org/10.1039/C3CS60336A

2. Lehn, J.-M. Angew. Chem. Int. Ed. 2015, 54, 3276-3289.

https://doi.org/10.1002/anie.201409399

3. Ramström, O.; Lehn, J.-M. Nat. Rev. Drug Discov. 2002, 1, 26-36.

https://doi.org/10.1038/nrd704

4. Mondal, M.; Hirsch, A. K. H. Chem. Soc. Rev. 2015, 44, 2455-2488.

https://doi.org/10.1039/C4CS00493K

5. Huang, R.; Leung, I. Molecules 2016, 21, 910.

https://doi.org/10.3390/molecules21070910

6. Frei, P.; Hevey, R.; Ernst, B. Chem. Eur. J. 2019, 25, 60-73.

https://doi.org/10.1002/chem.201803365

7. Nasr, G.; Petit, E.; Supuran, C. T.; Winum, J.-Y.; Barboiu, M. Bioorg. Med. Chem. Lett. 2009, 19, 6014-6017. https://doi.org/10.1016/i.bmcl.2009.09.047

8. Cheeseman, J. D.; Corbett, A. D.; Shu, R.; Croteau, J.; Gleason, J. L.; Kazlauskas, R. J. J. Am. Chem. Soc. 2002, 124, 5692-5701.

https://doi.org/10.1021/ja017099+ 
9. Corbett, A. D.; Cheeseman, J. D.; Kazlauskas, R. J.; Gleason, J. L. Angew. Chem. Int. Ed. 2004, 43, $2432-2436$. https://doi.org/10.1002/anie.200453769

10. Foxman, B. Am. J. Med. 2002, 113 (1, Suppl.1), 5-13.

https://doi.org/10.1016/S0002-9343(02)01054-9

11. Hooton, T. M.; Roberts, P. L.; Cox, M. E.; Stapleton, A. E. N. Engl. J. Med. 2013, 369, 1883-1891. https://doi.org/10.1056/NEJMoa1302186

12. Spaulding, C.; Hultgren, S. Pathogens 2016, 5, 30. https://doi.org/10.3390/pathogens5010030

13. Justice, S. S.; Hung, C.; Theriot, J. A.; Fletcher, D. A.; Anderson, G. G.; Footer, M. J.; Hultgren, S. J. Proc. Natl. Acad. Sci. U.S.A. 2004, 101, 1333-1338.

https://doi.org/10.1073/pnas.0308125100

14. Kleeb, S.; Pang, L.; Mayer, K.; Eris, D.; Sigl, A.; Preston, R. C.; Zihlmann, P.; Sharpe, T.; Jakob, R. P.; Abgottspon, D.; Hutter, A. S.; Scharenberg, M.; Jiang, X.; Navarra, G.; Rabbani, S.; Smiesko, M.; Lüdin, N.; Bezençon, J.; Schwardt, O.; Maier, T.; Ernst, B. J. Med. Chem. 2015, 58, 2221-2239.

https://doi.org/10.1021/jm501524q

15. Kleeb, S.; Jiang, X.; Frei, P.; Sigl, A.; Bezençon, J.; Bamberger, K.; Schwardt, O.; Ernst, B. J. Med. Chem. 2016, 59, 3163-3182.

https://doi.org/10.1021/acs.jmedchem.5b01923

16. Schönemann, W.; Kleeb, S.; Dätwyler, P.; Schwardt, O.; Ernst, B. Can. J. Chem. 2016, 94, 909-919. https://doi.org/10.1139/cjc-2015-0582

17. Mayer, K.; Eris, D.; Schwardt, O.; Sager, C. P.; Rabbani, S.; Kleeb, S.; Ernst, B. J. Med. Chem. 2017, 60, 56465662.

https://doi.org/10.1021/acs.jmedchem.7b00342

18. Mydock-McGrane, L. K.; Cusumano, Z. T.; Janetka, J. W. Expert Opin. Ther. Pat. 2015, 26, 175-197. https://doi.org/10.1517/13543776.2016.1131266

19. Mydock-McGrane, L.; Cusumano, Z.; Han, Z.; Binkley, J.; Kostakioti, M.; Hannan, T.; Pinkner, J. S.; Klein, R.; Kalas, V.; Crowley, J.; Rath, N. P.; Hultgren, S. J.; Janetka, J. W. J. Med. Chem. 2016, 59, 9390-9408. https://doi.org/10.1021/acs.jmedchem.6b00948

20. Jarvis, C.; Han, Z.; Kalas, V.; Klein, R.; Pinkner, J. S.; Ford, B.; Binkley, J.; Cusumano, C. K.; Cusumano, Z.; Mydock-McGrane, L.; Hultgren, S. J.; Janetka, J. W. ChemMedChem 2016, 11, 367-373.

https://doi.org/10.1002/cmdc.201600006

21. Frei, P.; Pang, L.; Silbermann, M.; Eriş, D.; Mühlethaler, T.; Schwardt, O.; Ernst, B. Chem. Eur. J. 2017, 23, 11570-11577.

https://doi.org/10.1002/chem.201701601

22. Dirksen, A.; Dirksen, S.; Hackeng, T. M.; Dawson, P. E. J. Am. Chem. Soc. 2006, 128, 15602-15603. https://doi.org/10.1021/ja067189k

23. Sauer, M. M.; Jakob, R. P.; Eras, J.; Baday, S.; Eris, D.; Navarra, G.; Berneche, S.; Ernst, B.; Maier, T.; Glockshuber, R. Nat. Commun. 2016, 7, 1-13.

https://doi.org/10.1038/ncomms10738

24. Bhat, V. T.; Caniard, A. M.; Luksch, T.; Brenk, R.; Campopiano, D. J.; Greaney, M. F. Nat. Chem. 2010, 2, 490497.

https://doi.org/10.1038/nchem.658 
25. Bouckaert, J.; Berglund, J.; Schembri, M.; De Genst, E.; Cools, L.; Wuhrer, M.; Hung, C.-S.; Pinkner, J.; Slättegård, R.; Zavialov, A.; Choudhury, D.; Langermann, S.; Hultgren, S. J.; Wyns, L.; Klemm, P.; Oscarson, S.; Knight, S. D.; De Greve, H. Mol. Microbiol. 2005, 55, 441-455.

https://doi.org/10.1111/j.1365-2958.2004.04415.x

26. Ladame, S. Org. Biomol. Chem. 2008, 6, 219-226.

https://doi.org/10.1039/B714599C

27. Poulsen, S.-A. J. Am. Soc. Mass Spectrom. 2006, 17, 1074-1080.

https://doi.org/10.1016/j.jasms.2006.03.017

28. Clipson, A. J.; Bhat, V. T.; McNae, I.; Caniard, A. M.; Campopiano, D. J.; Greaney, M. F. Chem. Eur. J. 2012, 18, 10562-10570.

https://doi.org/10.1002/chem.201201507

29. Mondal, M.; Radeva, N.; Köster, H.; Park, A.; Potamitis, C.; Zervou, M.; Klebe, G.; Hirsch, A. K. H. Angew. Chem. Int. Ed. 2014, 53, 3259-3263.

https://doi.org/10.1002/anie.201309682

30. Mondal, M.; Radeva, N.; Fanlo-Virgós, H.; Otto, S.; Klebe, G.; Hirsch, A. K. H. Angew. Chem. Int. Ed. 2016, 55 (32), 9422-9426.

https://doi.org/10.1002/anie.201603074

31. Vincent, S.; Fu, J.; Fu, H.; Dieu, M.; Halloumi, I.; Kremer, L.; Xia, Y.; Pan, W. Chem. Commun. 2017, 53 (77), 10632-10635.

https://doi.org/10.1039/C7CC05251K

32. Carolina, D. D.; Eliezer, J. B.; Carlos, A. M. F. Mini-Rev. Med. Chem. 2007, 7, 1108-1119.

33. Yu, X.; Shi, L.; Ke, S. Bioorg. Med. Chem. Lett. 2015, 25, 5772-5776.

https://doi.org/10.1016/i.bmcl.2015.10.069

34. Misra, S.; Ghatak, S.; Patil, N.; Dandawate, P.; Ambike, V.; Adsule, S.; Unni, D.; Venkateswara Swamy, K.; Padhye, S. Bioorg. Med. Chem. 2013, 21, 2551-2559.

https://doi.org/10.1016/j.bmc.2013.02.033

35. Barman, S.; You, L.; Chen, R.; Codrea, V.; Kago, G.; Edupuganti, R.; Robertus, J.; Krug, R. M.; Anslyn, E. V. Eur. J. Med. Chem. 2014, 71 (Suppl. C), 81-90.

https://doi.org/10.1016/i.ejmech.2013.10.063

36. Burgeson, J. R.; Gharaibeh, D. N.; Moore, A. L.; Larson, R. A.; Amberg, S. M.; Bolken, T. C.; Hruby, D. E.; Dai, D. Bioorg. Med. Chem. Lett. 2013, 23, 5840-5843.

https://doi.org/10.1016/j.bmcl.2013.08.103

37. Chen, C.; Dolla, N. K.; Casadei, G.; Bremner, J. B.; Lewis, K.; Kelso, M. J. Bioorg. Med. Chem. Lett. 2014, 24, 595-600.

https://doi.org/10.1016/j.bmcl.2013.12.015

38. Pieczonka, A. M.; Strzelczyk, A.; Sadowska, B.; Mlostoń, G.; Stączek, P. Eur. J. Med. Chem. 2013,64 (Suppl. C), 389-395.

https://doi.org/10.1016/i.ejmech.2013.04.023

39. Maia, R. d. C.; Tesch, R.; Fraga, C. A. M. Expert Opin. Ther. Pat. 2014, 24, 1161-1170. https://doi.org/10.1517/13543776.2014.959491

40. Sonawane, S. J.; Kalhapure, R. S.; Govender, T. Eur. J. Pharm. Sci. 2017, 99 (Suppl. C), 45-65. https://doi.org/10.1016/j.ejps.2016.12.011

41. Jumde, V. R.; Mondal, M.; Gierse, R. M.; Unver, M. Y.; Magari, F.; van Lier, R. C. W.; Heine, A.; Klebe, G.; Hirsch, A. K. H. ChemMedChem 2018, 13, 2266-2270. 
https://doi.org/10.1002/cmdc.201800446 